Research Article

\title{
Substituted-Amidine Functionalized Monocyclic $\beta$-Lactams: Synthesis and In Vitro Antibacterial Profile
}

\author{
Lili He, ${ }^{1}$ Lijuan Zhai, ${ }^{1}$ Jian Sun, ${ }^{1}$ Jingwen Ji, ${ }^{1}$ Jinbo Ji, ${ }^{1}$ Yuanbai Liu, ${ }^{1}$ Yangxiu Mu, ${ }^{1}$ \\ Yuanyu Gao, ${ }^{1}$ Dong Tang, ${ }^{1}$ Rui Jiang, ${ }^{1}$ Ko Ko Myo, ${ }^{1,2}$ Zaw Min Thu $\mathbb{D}^{1,2}$ Haikang Yang, \\ Zafar Iqbal $\mathbb{D},{ }^{1}$ and Zhixiang Yang $\mathbb{D}^{1}$ \\ ${ }^{1}$ Ningxia Centre of Organic Synthesis and Engineering Technology, Ningxia Academy of Agriculture and Forestry Sciences, \\ No. 590, Huanghe East Road, Jinfeng District, Yinchuan, Ningxia 750002, China \\ ${ }^{2}$ Department of Chemistry, Kalay University, Kalay 03044, Sagaing Region, Myanmar
}

Correspondence should be addressed to Zafar Iqbal; zich_kiu@yahoo.co.uk and Zhixiang Yang; yangzhixiang8@163.com

Received 23 March 2021; Revised 7 July 2021; Accepted 12 July 2021; Published 28 July 2021

Academic Editor: Hideto Miyabe

Copyright ( 2021 Lili He et al. This is an open access article distributed under the Creative Commons Attribution License, which permits unrestricted use, distribution, and reproduction in any medium, provided the original work is properly cited.

Background. Owing to the intrinsic stability against common $\beta$-lactamases and metallo-lactamases, monobactams gathered special attention in antibiotic drug development. However, so far, aztreonam is the only monobactam approved by FDA for clinical use. We designed new derivatives of aztreonam to enhance its antibacterial efficacy. Methods. We synthesized a series of monocyclic $\beta$-lactams by modifying mainly at the $\mathrm{C} 3$ position of azetidinone ring. $\mathrm{NH}_{2}$ group at $\mathrm{C} 3$ of azetidinone was attached to thiazole and thiadiazole which in turn was linked to nitrogenous heterocyclic rings via amidine moieties. We then investigated the in vitro antibacterial activities of synthesized compounds against ten bacterial strains of clinical interest in comparison to aztreonam and ceftazidime. Results. All compounds showed improved antibacterial activities against tested strains compared to reference drugs. Compounds 14d and $\mathbf{1 4} \mathbf{e}$ were most potent and showed the highest potency against all bacterial strains, with MIC values ranging from $0.25 \mu \mathrm{g} / \mathrm{mL}$ to $8 \mu \mathrm{g} / \mathrm{mL}$, as compared to aztreonam (MIC $16 \mu \mathrm{g} / \mathrm{mL}$ to $>64 \mu \mathrm{g} / \mathrm{mL}$ ) and ceftazidime (MIC $>64 \mu \mathrm{g} / \mathrm{mL}$ ). These compounds (14d and 14e) may be valuable lead targets against multidrug-resistant Gram-negative bacteria.

\section{Introduction}

Continuous increase of $\beta$-lactamases [1], in association with variable resistance mechanisms [2,3], has managed the generation of multidrug-resistant (MDR) bacteria [4] over the years. Of these lactamases, extended-spectrum $\beta$-lactamases (ESBLs) are the prime cause of resistance in MDR bacteria that compromises the effectiveness of antibiotic therapy. The fact that present antibacterial drugs may be ineffective in the future requires continuous development of new antibiotics capable of combating bacterial resistance over time. To this end, different classes of $\beta$-lactams [5] are still growing areas of research despite the increasing number (more than 1000) [6] of $\beta$-lactamases.

$\beta$-Lactams are the broad spectrum and most widely used antibiotics for the treatment of serious bacterial infections. Among various classes of $\beta$-lactams including cephalosporins, carbapenems, and penicillins [5], monocyclic- $\beta$-lactams $[7,8]$ are inherently resistant to common $\beta$-lactamases and metallolactamases (MBLs). Since the discovery of nocardicins and other monobactams from Nocardia uniformis and Pseudomonas strains, fine-tuning of the azetidinone ring is the common phenomenon to acquire the optimal potency. As a result, a vast variety of synthetic monobactam derivatives have been evaluated for antibacterial activity. The data gathered around the years revealed that the sulfonic acid group on the N1 position of the lactam ring is essential for the activation of the carbonyl group, whereas substitution at C3 and C4 maintains the stability of the molecule and plays part toward the antibacterial activity [8].

Nonetheless, despite enormous efforts, only one monobactam has been approved for clinical applications so far. Aztreonam (Figure 1) as the single FDA-approved monobactam shows a broad spectrum of activities against aerobic 


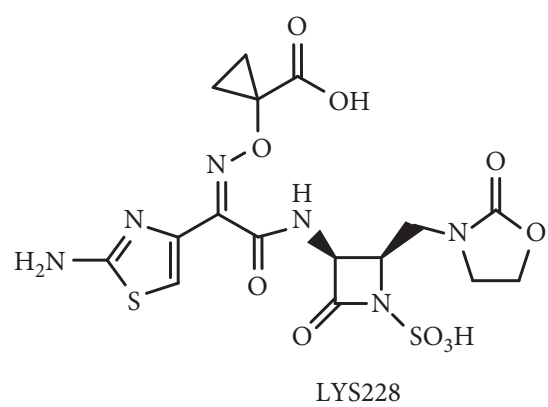

(a)<smiles>C[C@H]1[C@H](NC(=O)/C(=N\OC(C)(C)C(=O)O)c2csc(N)n2)C(=O)N1C(=O)O</smiles>

(b)<smiles>CC1(C)[C@H](NC(=O)/C(=N\OCc2cc(=O)c(O)cn2O)c2csc(N)n2)C(=O)N1OS(=O)(=O)O</smiles>

BAL30072

(c)

FIgURE 1: Structures of currently approved aztreonam and other monobactams in clinical trials.

and anaerobic Gram-negative bacteria [9]. Although resistant to MBLs, aztreonam is susceptible to most of the ESBLs, AmpCs, and KPCs coproduced by the MBL producing Enterobacteriaceae strains [10-12]. Therefore, many researchers are trying to improve the efficacy of aztreonam by introducing variable substituents at the C3 and C4 positions of the azetidinone ring. Recently, Reck et al. synthesized a number of compounds with variable substituents at C3 and C4 positions of azetidinone and identified a compound (LYS228) (Figure 1) that is resistant to all classes of $\beta$-lactamases. It also showed potent activity against carbapenemresistant Enterobacteriaceae (CRE) [13]. BAL30072 (Figure 1), another monobactam in phase-I clinical trials in Switzerland, demonstrated stability against MBLs, class $\mathrm{C}$, and some of the class $\mathrm{A}$ and $\mathrm{D} \beta$-lactamases [14].

As part of our ongoing efforts on the synthesis of monocyclic $\beta$-lactams, we previously reported the synthesis and in vitro antibacterial activity of a series of monobactams containing urea moiety. Although a few of the compounds exhibited improved antibacterial activity, none of them could achieve the acceptable MIC value against all tested strains [15]. We, therefore, decided to replace the urea moiety with amidine based on our own experience, and literature report on the previous amidine substituted monocyclic $\beta$-lactams [16]. Inspired from the literature and our previous data, the following substitutions were emphasized in the designing of final target molecules: (i) $\mathrm{N} 1$ position of the azetidinone ring was substituted with $\mathrm{OSO}_{3} \mathrm{H}$ or $\mathrm{SO}_{3} \mathrm{H}$, (ii) $\mathrm{NH}_{2}$ at $\mathrm{C} 3$ of the azetidinone was attached to thiazole or thiadiazole moiety which was further linked to heterocyclic (four to six membered nitrogenous) ring via a linker containing amidine and carboxylic groups, and (iii) $\mathrm{C} 4$ of the azetidinone ring was substituted with methyl or geminal dimethyl groups. Thus, designed molecules 14a-e, 14g, 18a, 18b, and 18d-e (Figure 2) were recognized as our synthetic targets. Herein, we describe their synthesis and antimicrobial activities in vitro against ten bacterial strains containing variable $\beta$-lactamases.

\section{Materials and Methods}

All ${ }^{1} \mathrm{H}$ NMR and ${ }^{13} \mathrm{C}$ NMR spectra were recorded on a Bruker AVANCE NEO $400 \mathrm{NMR}$ operating at $400 \mathrm{MHz}$ for
${ }^{1} \mathrm{H}$ and $100 \mathrm{MHz}$ for ${ }^{13} \mathrm{C}$, respectively, and signals for NMR data are described as chemical shifts. All NMR spectra were recorded in deuterated solvents such as $\mathrm{CDCl}_{3}, \mathrm{CD}_{3} \mathrm{OD}$, or DMSO- $d_{6}$ containing tetramethylsilane (TMS) an internal standard. Chemical shift $(\delta)$ values are denoted in parts per million (ppm), whereas coupling constant $(J)$ values are provided in Hertz $(\mathrm{Hz})$. Signal multiplicities are reported as follows: s, for singlet; br s, for broad singlet; $d$, for doublet; $t$, for triplet; and $\mathrm{m}$, for multiplet. Final compounds were purified by Preparative HPLC using Agilent 1260 Infinity II System equipped with Agilent 10 prep-C18 $250 \times 21.2 \mathrm{~mm}$ column. Acetonitrile/water containing $0.1 \%$ trifluoroacetic acid or acetonitrile/water containing $0.1 \%$ formic acid was used as a solvent system for gradient elution at $22^{\circ} \mathrm{C}$. LC-MS spectra were recorded on Agilent 1260 Infinity II System using either negative $\left(\mathrm{ES}^{-}\right)$or positive $\left(\mathrm{ES}^{+}\right)$ionization modes. HRMS spectra were performed on a Waters Xevo G2-XS QTof using either $\mathrm{ES}^{-}$or $\mathrm{ES}^{+}$ionization modes. Column chromatographic separation and purification were performed using glass columns filled with Qingdao Inc. Silica Gel: CC Grade (230-400 Mesh). Commercially available dry solvents were used in all synthesis experiments whereas commercial reagents were purchased from suppliers and used without purification.

\subsection{Chemistry}

2.1.1. Synthesis of Compound 2. A mixture of a $\mathrm{Co}(\mathrm{III})-$ catalyst $(7.0 \mathrm{~g}, 8.4 \mathrm{mmol})$ and $4 \AA$ molecular sieves $(10 \mathrm{~g})$ in tert-butyl methyl ether $(50 \mathrm{~mL})$ was treated with methyl $(R)$ oxirane-2-carboxylate $(45.0 \mathrm{~g}, 441 \mathrm{mmol})$ and 4-hydroxybenzonitrile (1) $(26.3 \mathrm{~g}, 220 \mathrm{mmol})$. The resulting mixture was stirred at room temperature for 48 hours, and the precipitates formed were filtered through celite pad. The filter cake was washed with ether, and the filtrate was evaporated under reduced pressure to afford a dark brown residue. The crude product was purified by column chromatography to yield the title compound $2(79.0 \mathrm{~g}, 81.1 \%$ yield) as a brown oil. ${ }^{1} \mathrm{H}$ NMR $\left(400 \mathrm{MHz}, \mathrm{DMSO}-d_{6}\right): \delta 3.68$ $(\mathrm{s}, 3 \mathrm{H}), 4.26(\mathrm{~m}, 2 \mathrm{H}), 4.49(\mathrm{~m}, 1 \mathrm{H}), 5.96(\mathrm{~s}, 1 \mathrm{H}), 7.11(\mathrm{~d}$, $J=8.96 \mathrm{~Hz}, 2 \mathrm{H}), 7.77(\mathrm{~d}, J=9.04 \mathrm{~Hz}, 2 \mathrm{H})$. LC-MS $[\mathrm{M}+\mathrm{H}]^{+}$ $\mathrm{m} / z 222.1$ (calcd for $\mathrm{C}_{11} \mathrm{H}_{11} \mathrm{NO}_{4}, 221.07$ ). 


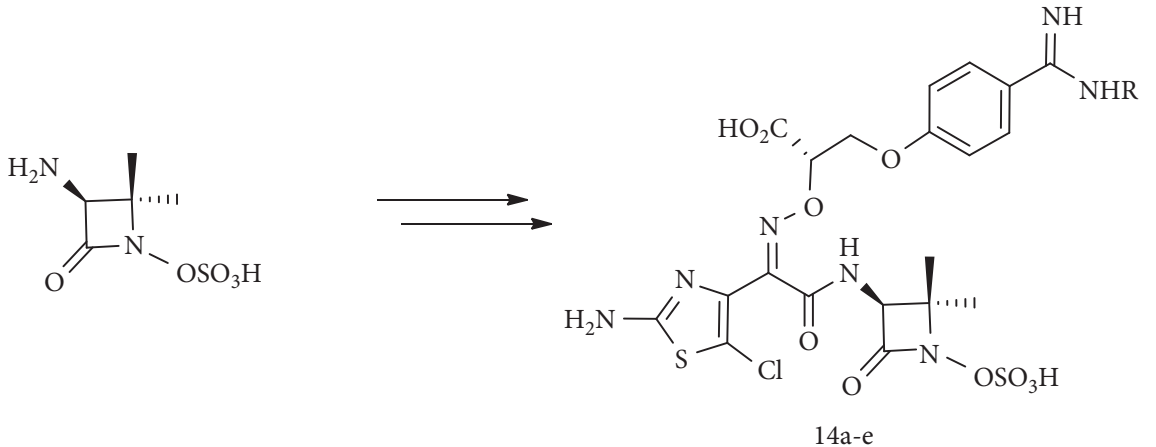

(a)
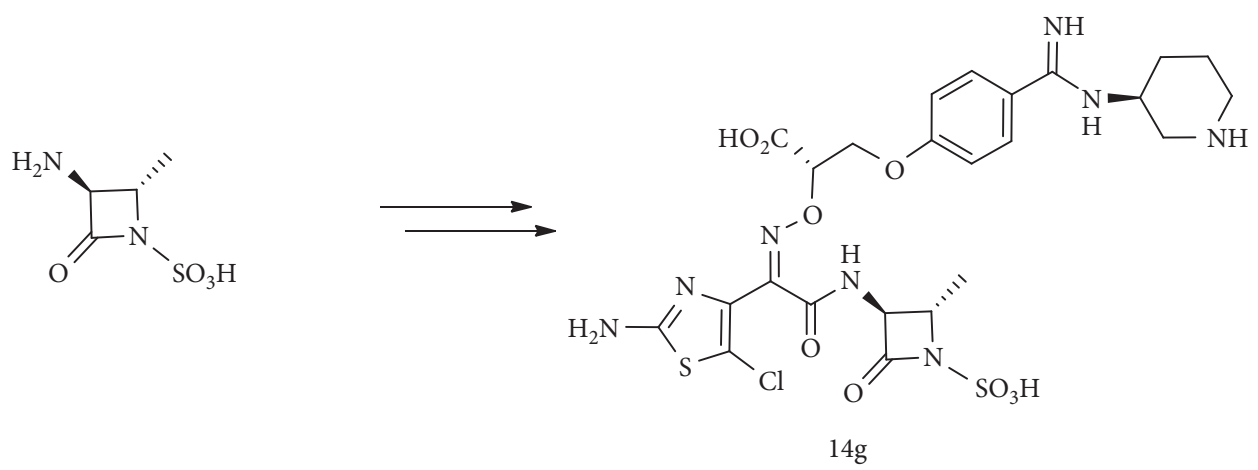

(b)
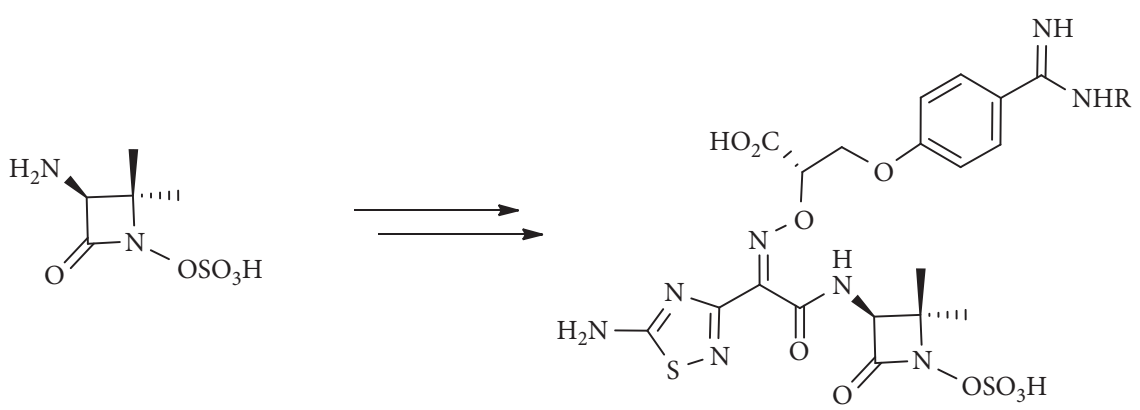

$18 \mathrm{a}, \mathrm{b}$ and $18 \mathrm{~d}-\mathrm{f}$

(c)

Figure 2: General structures of the target compounds.

2.1.2. Synthesis of Compound 3. A mixture of compound 2 $(36.6 \mathrm{~g}, 165 \mathrm{mmol})$ in anhydrous methanol $(160 \mathrm{~mL})$ was cooled to $0^{\circ} \mathrm{C}$ in a sealed vessel. Anhydrous $\mathrm{HCl}$ gas was bubbled through the reaction solution until saturation. The flask was sealed and stirred at $0^{\circ} \mathrm{C}$ to rt for 18 hours resulting in the formation of suspension. The solid was filtered and washed with diethyl ether to yield the desired compound 3 $(29 \mathrm{~g})$ as an $\mathrm{HCl}$ salt. The mother liquor was concentrated to precipitate another crop of solid which was collected and washed with ether to afford the additional desired compound $(9.89 \mathrm{~g}$ ) (totally $38.9 \mathrm{~g}$ of the desired compound obtained, $81.5 \%$ yield) as a light green solid. ${ }^{1} \mathrm{H}$ NMR $\left(400 \mathrm{MHz}, \mathrm{DMSO}-d_{6}\right): \delta 3.66(\mathrm{~s}, 3 \mathrm{H}), 4.24(\mathrm{~s}, 3 \mathrm{H})$, $4.27-4.31(\mathrm{~m}, 2 \mathrm{H}), 4.48(\mathrm{t}, J=4.4 \mathrm{~Hz}, 1 \mathrm{H}), 7.16(\mathrm{~d}, J=9.1 \mathrm{~Hz}$, $2 \mathrm{H}), 8.09(\mathrm{~d}, J=9.1 \mathrm{~Hz}, 2 \mathrm{H})$. LC-MS $[\mathrm{M}+\mathrm{H}]^{+} \mathrm{m} / z 254.1 .1$ (calcd for $\mathrm{C}_{12} \mathrm{H}_{15} \mathrm{NO}_{5}, 253.10$ ).
2.1.3. Synthesis of Compounds $\mathbf{9 a}-\boldsymbol{f}$. Compounds $\mathbf{9 a}-\mathbf{f}$ were synthesized according to Scheme 1 using general procedures described for a representative compound for each step as follows:

5a: to a solution of compound $3(1.0 \mathrm{~g}, 3.45 \mathrm{mmol})$ in anhydrous methanol $(3 \mathrm{~mL})$, triethylamine $(0.38 \mathrm{~g}$, $3.8 \mathrm{mmol}$ ) and tert-butyl 4-aminopiperidine-1-carboxylate $(0.69 \mathrm{~g}, 3.45 \mathrm{mmol})$ were added at $0^{\circ} \mathrm{C}$. The resulting mixture was stirred at room temperature overnight followed by the evaporation of solvent till dryness to afford a residue. The residue was purified by column chromatography to furnish the desired compound 5 a $\left(1.0 \mathrm{~g}, 69 \%\right.$ yield) as a white solid. ${ }^{1} \mathrm{H}$ NMR (400 MHz, DMSO- $\left.d_{6}\right): \delta 1.38(\mathrm{~s}, 9 \mathrm{H}), 1.54-1.43$ (m, 2H), 1.82-1.93 (m, 2H), 2.60-2.90 (m, 2H), 3.64 (s, 
$3 \mathrm{H}), 3.90-4.00(\mathrm{~m}, 3 \mathrm{H}), 4.12-4.28(\mathrm{~m}, 2 \mathrm{H}), 4.44-4.50$ $(\mathrm{m}, 1 \mathrm{H}), 5.98(\mathrm{~d}, J=6.1 \mathrm{~Hz}, 1 \mathrm{H}), 7.22(\mathrm{~d}, J=8.8 \mathrm{~Hz}$, 2H), $7.69(\mathrm{~d}, J=8.8 \mathrm{~Hz}, 2 \mathrm{H}), 9.43$ (s, 1H).LC-MS $[\mathrm{M}+\mathrm{H}]^{+} m / z 422.2$ (calcd for $\mathrm{C}_{21} \mathrm{H}_{31} \mathrm{~N}_{3} \mathrm{O}_{6}, 421.22$ ).

6a : to the solution of compound $5 \mathbf{a}(1.0 \mathrm{~g}, 2.37 \mathrm{mmol})$ in THF $(2 \mathrm{~mL})$, a solution of sodium hydroxide $(0.2 \mathrm{~g}$, $4.74 \mathrm{mmol})$ in water $(1 \mathrm{~mL})$ was added at $0^{\circ} \mathrm{C}$ and then stirred at rt for 5 hours. THF was removed, and the aqueous phase was neutralized to $\mathrm{pH} 5$ by $1 \mathrm{~N}$ aqueous $\mathrm{HCl}$. The resulting mixture was lyophilized to afford crude compound $\mathbf{6 a}(0.97 \mathrm{~g}$, containing $\mathrm{NaCl}$ salt) as a white solid. The crude product was directly used for the next step without purification. ${ }^{1} \mathrm{H}$ NMR $(400 \mathrm{MHz}$, DMSO- $d_{6}$ ): $\delta 1.41$ (s, 9H), 1.49 (br s, 2H), 1.92 (br s, 2H), 2.84 (br s, 2H), 3.86 (br s, $1 \mathrm{H}), 4.00$ (br s, $4 \mathrm{H}), 4.26$ (d, J=9.8 Hz, 1H), $7.12(\mathrm{~s}, 2 \mathrm{H}), 7.74$ (s, 2H).LC-MS $[\mathrm{M}+\mathrm{H}]^{+} m / z 408.2$ (calcd for $\mathrm{C}_{20} \mathrm{H}_{29} \mathrm{~N}_{3} \mathrm{O}_{6}, 407.21$ ).

$7 \mathbf{a}$ : to a solution of compound $\mathbf{6 a}(0.97 \mathrm{~g}, 2.37 \mathrm{mmol})$ in $\mathrm{MeOH}(2 \mathrm{~mL})$, a solution of diazo(diphenyl)methane $\left(\mathrm{Ph}_{2} \mathrm{CN}_{2}, 0.42 \mathrm{~g}, 3.56 \mathrm{mmol}\right)$ in $\mathrm{CH}_{2} \mathrm{Cl}_{2}(1.5 \mathrm{~mL})$ was slowly added. The resulting mixture was stirred at $\mathrm{rt}$ overnight and the solvent was concentrated to dryness. The crude product was purified by column chromatography to give product $7 \mathbf{a}(1.1 \mathrm{~g}, 80 \%$ yield in two steps) as a white solid. ${ }^{1} \mathrm{H}$ NMR $\left(400 \mathrm{MHz}, \mathrm{DMSO}-d_{6}\right)$ : $\delta 1.39(\mathrm{~s}, 9 \mathrm{H}), 1.42-1.52(\mathrm{~m}, 2 \mathrm{H}), 1.87-1.92(\mathrm{~m}, 2 \mathrm{H})$, 2.82 (br s, $2 \mathrm{H}), 3.90-4.00(\mathrm{~m}, 3 \mathrm{H}), 4.30-4.42(\mathrm{~m}, 2 \mathrm{H})$, $4.62-4.65(\mathrm{~m}, 1 \mathrm{H}), 6.48(\mathrm{~d}, J=7.6 \mathrm{~Hz}, 1 \mathrm{H}), 6.84(\mathrm{~s}, 1 \mathrm{H})$, $7.09(\mathrm{~d}, J=8.8 \mathrm{~Hz}, 2 \mathrm{H}), 7.22-7.41(\mathrm{~m}, 10 \mathrm{H}), 7.69(\mathrm{~d}$, $J=8.8 \mathrm{~Hz}, 2 \mathrm{H}), 9.10$ (br s, $1 \mathrm{H}), 9.38$ (br s, 1H). LC-MS $[\mathrm{M}+\mathrm{H}]^{+} m / z 574.1$ (calcd for $\mathrm{C}_{33} \mathrm{H}_{39} \mathrm{~N}_{3} \mathrm{O}_{6}, 573.28$ ).

8a: to a solution of compound $7 \mathbf{a}(1.2 \mathrm{~g}, 2.1 \mathrm{mmol}), \mathrm{N}$ hydroxyphthalimide $(1.03 \mathrm{~g}, 6.3 \mathrm{mmol})$, and triphenylphosphine $(1.7 \mathrm{~g}, 6.3 \mathrm{mmol})$ in anhydrous THF $(5 \mathrm{~mL})$, a solution of diethyl azodicarboxylate $(1.09 \mathrm{~g}$, $6.3 \mathrm{mmol}$ ) was added dropwise at $0^{\circ} \mathrm{C}$. The reaction mixture was stirred at rt overnight followed by the evaporation of THF to furnish the crude product, which was purified by column chromatography to afford compound $\mathbf{8 a}(1.0 \mathrm{~g}, 66.7 \%$ yield) as white solid. ${ }^{1} \mathrm{H}$ NMR (400 MHz, DMSO- $\left.d_{6}\right): \delta 1.42$ (s, 9H), $1.44-1.53(\mathrm{~m}, 2 \mathrm{H}), 1.92-1.96(\mathrm{~m}, 2 \mathrm{H}), 2.82$ (br s, $2 \mathrm{H})$, 3.92-4.16 (m, 3H), 4.68 (br s, $2 \mathrm{H}), 5.48$ (br s, $1 \mathrm{H}), 6.98$ $(\mathrm{s}, 1 \mathrm{H}), 7.11(\mathrm{~d}, J=8.6 \mathrm{~Hz}, 2 \mathrm{H}), 7.26-7.48(\mathrm{~m}, 10 \mathrm{H})$, $7.75(\mathrm{~d}, J=8.6 \mathrm{~Hz}, 2 \mathrm{H}), 7.86(\mathrm{~s}, 4 \mathrm{H}), 9.24$ (br s, $1 \mathrm{H}), 9.40$ (br s, 1H). LC-MS $[\mathrm{M}+\mathrm{H}]^{+} \mathrm{m} / z 719.3$ (calcd for $\mathrm{C}_{41} \mathrm{H}_{42} \mathrm{~N}_{4} \mathrm{O}_{8}, 718.30$ ).

9a: to the solution of compound $8 \mathbf{a}(0.33 \mathrm{~g}, 0.45 \mathrm{mmol})$ in anhydrous ethanol $(5 \mathrm{~mL})$, hydrazine monohydrate $(23 \mu \mathrm{L}, 0.52 \mathrm{mmol})$ was added at $0^{\circ} \mathrm{C}$. The resulting mixture was stirred at $\mathrm{rt}$ for 3.5 hours, filtered off and washed with ethanol $(2 \times 5 \mathrm{~mL})$. The filtrate was evaporated to dryness and the residue was suspended in $\mathrm{CH}_{2} \mathrm{Cl}_{2}(10 \mathrm{~mL})$, filtered off and rinsed with $\mathrm{CH}_{2} \mathrm{Cl}_{2}$ $(2 \times 3 \mathrm{~mL})$. The filtrate was concentrated to give compound 9a $(0.26 \mathrm{~g}$, quantitative yield) as a pale yellow foam. The crude product was used for the next step without purification. ${ }^{1} \mathrm{H}$ NMR (400 MHz, DMSO- $\left.d_{6}\right): \delta$ $1.42(\mathrm{~s}, 9 \mathrm{H}), 1.42-1.54(\mathrm{~m}, 2 \mathrm{H}), 1.87-1.97(\mathrm{~m}, 2 \mathrm{H})$, 2.72-2.94 (m, 2H), 3.82-4.06 (m, 3H), 4.30-4.49 (m, 2H), 4.60-4.68 (m,1H), $6.91(\mathrm{~s}, 1 \mathrm{H}), 7.10(\mathrm{~d}, J=8.8 \mathrm{~Hz}, 2 \mathrm{H})$, 7.25-7.47 (m, 10H), $7.71(\mathrm{~d}, J=8.8 \mathrm{~Hz}, 2 \mathrm{H}), 9.15$ (br s, $4 \mathrm{H}$ ). LC-MS $[\mathrm{M}+\mathrm{H}]^{+} m / z 589.3$ (calcd for $\mathrm{C}_{33} \mathrm{H}_{40} \mathrm{~N}_{4} \mathrm{O}_{6}$, 588.29).

9b: ${ }^{1} \mathrm{H}$ NMR (400 MHz, DMSO- $\left.d_{6}\right): \delta 1.38$ (s, 9H), $1.43-1.49(\mathrm{~m}, 1 \mathrm{H}), 1.52-1.60(\mathrm{~m}, 1 \mathrm{H}), 1.72-1.82$ $(\mathrm{m}, 1 \mathrm{H}), 1.96-2.03(\mathrm{~m}, 1 \mathrm{H}), 2.91-3.04(\mathrm{~m}, 1 \mathrm{H})$, 3.33-3.39 (m, 3H), 3.75-3.82 (m, 1H), 4.36-4.47 $(\mathrm{m}, 2 \mathrm{H}), 4.62-4.65(\mathrm{~m}, 1 \mathrm{H}), 6.45(\mathrm{~s}, 2 \mathrm{H}), 6.90(\mathrm{~s}, 1 \mathrm{H})$, $7.07(\mathrm{~d}, J=8.9 \mathrm{~Hz}, 2 \mathrm{H}), 7.23-7.32(\mathrm{~m}, 4 \mathrm{H}), 7.33-7.40$ (m, 4H), 7.42-7.45 (m, 2H), 7.69 (d, J=8.9 Hz, 2H). LCMS $[\mathrm{M}+\mathrm{H}]^{+} m / z 589.3$ (calcd for $\mathrm{C}_{33} \mathrm{H}_{40} \mathrm{~N}_{4} \mathrm{O}_{6}, 588.29$ ).

9c: ${ }^{1} \mathrm{H}$ NMR (400 MHz, DMSO- $\left.d_{6}\right): \delta 1.39(\mathrm{~s}, 9 \mathrm{H})$, $1.43-1.49(\mathrm{~m}, 1 \mathrm{H}), 1.51-1.61(\mathrm{~m}, 1 \mathrm{H}), 1.74-1.82(\mathrm{~m}$, $1 \mathrm{H}), 1.96-2.04(\mathrm{~m}, 1 \mathrm{H}), 2.92-3.04(\mathrm{~m}, 1 \mathrm{H}), 3.40-3.47$ $(\mathrm{m}, 3 \mathrm{H}), 3.74-3.83(\mathrm{~m}, 1 \mathrm{H}), 4.37-4.44(\mathrm{~m}, 2 \mathrm{H}), 4.64$ $(\mathrm{t}, J=3.9 \mathrm{~Hz}, 1 \mathrm{H}), 6.46(\mathrm{~s}, 2 \mathrm{H}), 6.90(\mathrm{~s}, 1 \mathrm{H}), 7.09$ $(\mathrm{d}, J=8.7 \mathrm{~Hz}, 2 \mathrm{H}), \quad 7.22-7.32(\mathrm{~m}, 4 \mathrm{H}), \quad 7.33-7.40$ (m, 4H), 7.41-7.47 (m, 2H), 7.69 (d, J=8.7 Hz, 2H). LCMS $[\mathrm{M}+\mathrm{H}]^{+} m / z$ 589.3(calcd for $\mathrm{C}_{33} \mathrm{H}_{40} \mathrm{~N}_{4} \mathrm{O}_{6}, 588.29$ ). 9d: ${ }^{1} \mathrm{H}$ NMR $\left(400 \mathrm{MHz}, \mathrm{DMSO}-d_{6}\right): \delta 1.34(\mathrm{~s}, 9 \mathrm{H})$, 1.80-1.99 (m, 1H), 2.11-2.18 (m, 1H), 3.33-3.39 $(\mathrm{m}, 3 \mathrm{H}), 3.52-3.61(\mathrm{~m}, 1 \mathrm{H}), 4.27-4.39(\mathrm{~m}, 3 \mathrm{H})$, 4.54-4.60 (m, 1H), $6.38(\mathrm{~s}, 2 \mathrm{H}), 6.82(\mathrm{~s}, 1 \mathrm{H}), 7.02$ $(\mathrm{d}, J=7.8 \mathrm{~Hz}, 2 \mathrm{H}), \quad 7.17-7.24(\mathrm{~m}, 4 \mathrm{H}), \quad 7.26-7.33$ (m, 4H), 7.34-7.38 (m, 2H), 7.63 (d, J=7.8 Hz, 2H). LCMS $[\mathrm{M}+\mathrm{H}]^{+} m / z 575.3$ (calcd for $\mathrm{C}_{32} \mathrm{H}_{38} \mathrm{~N}_{4} \mathrm{O}_{6}, 574.28$ ).

9e: ${ }^{1} \mathrm{H}$ NMR (400 MHz, DMSO- $\left.d_{6}\right): \delta 1.41(\mathrm{~s}, 9 \mathrm{H})$, 1.97-2.07 (m, 1H), 2.17-2.27 (m, 1H), 3.40-3.47 $(\mathrm{m}, 3 \mathrm{H}), 3.60-3.68(\mathrm{~m}, 1 \mathrm{H}), 4.35-4.47(\mathrm{~m}, 3 \mathrm{H})$, $4.62-4.65(\mathrm{~m}, 1 \mathrm{H}), 6.45(\mathrm{~s}, 2 \mathrm{H}), 6.90(\mathrm{~s}, 1 \mathrm{H}), 7.07$ $(\mathrm{d}, J=8.8 \mathrm{~Hz}, 2 \mathrm{H}), 7.22-7.32(\mathrm{~m}, 4 \mathrm{H}), \quad 7.33-7.40$ (m, 4H), 7.41-7.46 (m, 2H), $7.73(\mathrm{~d}, J=8.8 \mathrm{~Hz}, 2 \mathrm{H})$. LCMS $[\mathrm{M}+\mathrm{H}]^{+} m / z 575.3$ (calcd for $\mathrm{C}_{32} \mathrm{H}_{38} \mathrm{~N}_{4} \mathrm{O}_{6}, 574.28$ ). 9f: ${ }^{1} \mathrm{H}$ NMR $\left(400 \mathrm{MHz}, \mathrm{DMSO}-d_{6}\right): \delta 1.39(\mathrm{~s}, 9 \mathrm{H})$, 3.41-3.46 (m, 3H), 3.85-3.92 (m, 2H), 4.18-4.26 $(\mathrm{m}, 1 \mathrm{H}), 4.34-4.38(\mathrm{~m}, 2 \mathrm{H}), 4.01-4.45(\mathrm{~m}, 1 \mathrm{H})$, 4.61-4.64 (m,1H), $6.44(\mathrm{~s}, 2 \mathrm{H}), 6.90(\mathrm{~s}, 1 \mathrm{H}), 7.04$ $(\mathrm{d}, J=8.8 \mathrm{~Hz}, 2 \mathrm{H}), 7.22-7.31(\mathrm{~m}, 4 \mathrm{H}), \quad 7.33-7.40$ (m, 4H), 7.41-7.45 (m, 2H), 7.75 (d, J=8.8 Hz, 2H). LCMS $[\mathrm{M}+\mathrm{H}]^{+} m / z$ 561.2. (calcd for $\mathrm{C}_{31} \mathrm{H}_{36} \mathrm{~N}_{4} \mathrm{O}_{6}, 560.26$ ).

2.1.4. Synthesis of Compounds 14a-e. Compounds 14a-e were synthesized according to Scheme 2 using general procedures described for a representative compound for each step as follows:

11a: to the solution of compound 9a (0.294 g, $0.50 \mathrm{mmol})$ in ethanol $(3 \mathrm{~mL})$ and chloroform $(3 \mathrm{~mL})$, 2-(2-((tert-butoxycarbonyl)amino)-5-chlorothiazol4-yl)-2-oxoacetic acid $10(0.151 \mathrm{~g}, 0.490 \mathrm{mmol})$ [17] was added. The reaction mixture was stirred at $\mathrm{rt}$ for 18 hours, concentrated under vacuo, and purified by flash column chromatography $(10-20 \% \mathrm{MeOH}$ in 

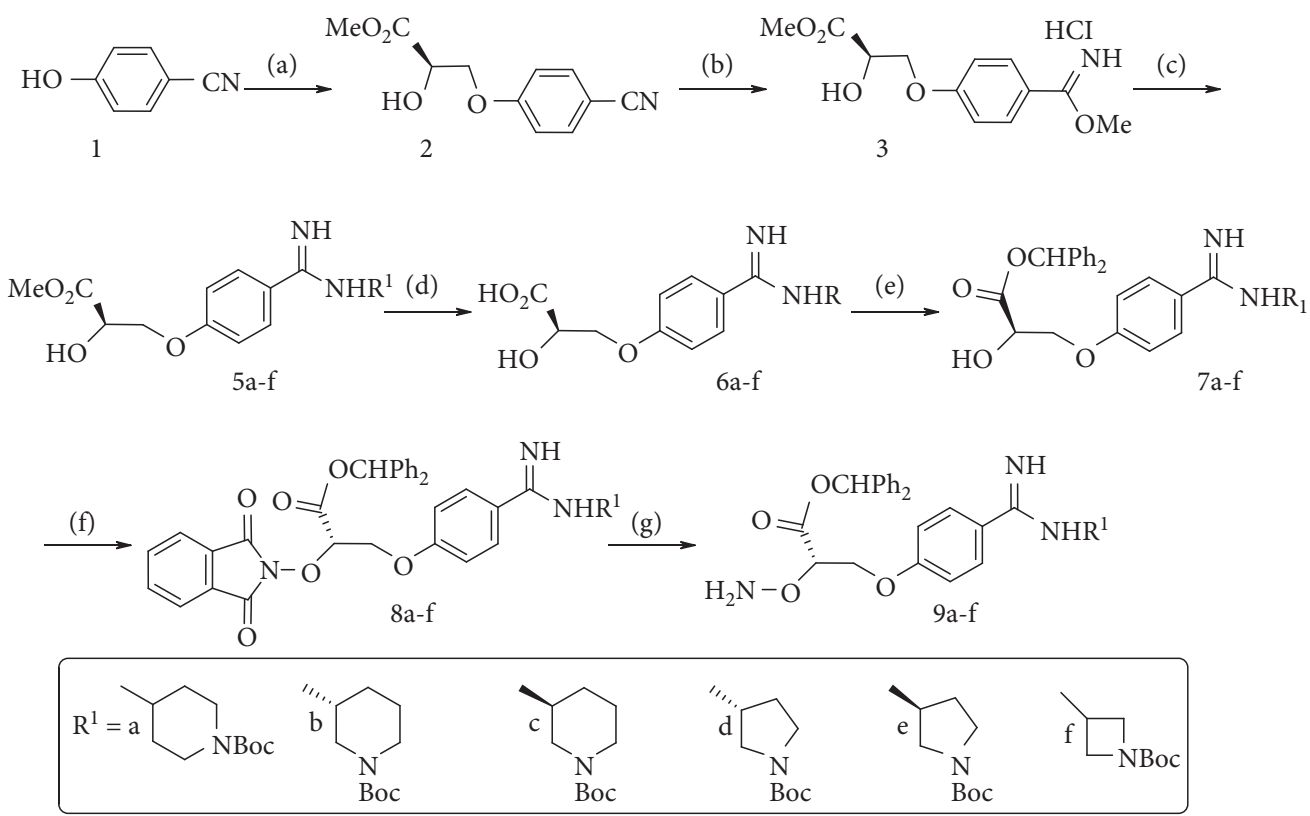

Scheme 1: Synthesis of compounds 9a-f. Reagents and conditions: (a) methyl (R)-oxirane-2-carboxylate, (salen)Co(III) complex, $4 \AA$ molecular sieves, MTBE, rt, 81\%; (b) $\mathrm{H}_{2}$ (gas), dry $\mathrm{MeOH}, 0^{\circ} \mathrm{C}-\mathrm{rt}, 82 \%$; (c) triethylamine, $\mathrm{H}_{2} \mathrm{~N}-\mathrm{R}_{\mathrm{a}-\mathrm{f}}, \mathrm{MeOH}, 0^{\circ} \mathrm{C}-\mathrm{rt}, 57-95 \%$; (d) $\mathrm{NaOH}$, THF-water, $0^{\circ} \mathrm{C}$, 75-99\%; (e) $\mathrm{Ph}_{2} \mathrm{CN}_{2}, \mathrm{CH}_{2} \mathrm{Cl}_{2}, \mathrm{rt}, 31-84 \%$; (f) PhthN-OH, DEAD, $\mathrm{PPh}_{3}, \mathrm{THF}, \mathrm{rt}, 33-66 \%$; $(\mathrm{g}) \mathrm{NH}_{2} \mathrm{NH}_{2} \cdot \mathrm{H}_{2} \mathrm{O}, \mathrm{EtOH} \mathrm{rt}$, quantitative.

$\left.\mathrm{CH}_{2} \mathrm{Cl}_{2}\right)$ to give compound $11 \mathrm{a}(0.31 \mathrm{~g}, 71 \%$ yield $)$ as a pale yellow solid. ${ }^{1} \mathrm{H}$ NMR $\left(400 \mathrm{MHz}, \mathrm{DMSO}-d_{6}\right): \delta$ $1.42(\mathrm{~s}, 9 \mathrm{H}), 1.46(\mathrm{~s}, 9 \mathrm{H}), 1.54-1.43(\mathrm{~m}, 2 \mathrm{H}), 1.86-1.96$ $(\mathrm{m}, 2 \mathrm{H}), 2.71-2.91(\mathrm{~m}, 2 \mathrm{H}), 3.84-4.03(\mathrm{~m}, 3 \mathrm{H})$, 4.43-4.57 (m, 2H), 5.05-5.12 (m,1H), $6.87(\mathrm{~s}, 1 \mathrm{H})$, $7.09(\mathrm{~d}, J=8.8 \mathrm{~Hz}, 2 \mathrm{H}), 7.20-7.30(\mathrm{~m}, 6 \mathrm{H}), 7.41-7.50$ (m, 4H), $7.68(\mathrm{~d}, J=8.8 \mathrm{~Hz}, 2 \mathrm{H}), 9.20(\mathrm{~s}, 1 \mathrm{H}), 9.38$ (s, $1 \mathrm{H}), 9.47$ (s, 1H), $11.9(\mathrm{~s}, 1 \mathrm{H})$. LC-MS $[\mathrm{M}+\mathrm{H}]^{+}$ $m / z 877.1$ and $[\mathrm{M}+\mathrm{H}+2]^{+} \mathrm{m} / z \quad 879.1$ (calcd for $\mathrm{C}_{43} \mathrm{H}_{49} \mathrm{ClN}_{6} \mathrm{O}_{10} \mathrm{~S}, 876.29$ ).

13a: to the solution of compound 11a (0.305 g, $0.350 \mathrm{mmol})$ in anhydrous DMF $(3.5 \mathrm{~mL}), \mathrm{DCC}(0.11 \mathrm{~g}$, $0.52 \mathrm{mmol}$ ) and HOBT $(70.0 \mathrm{mg}, 0.52 \mathrm{mmol})$ were added. The reaction mixture was stirred at $\mathrm{rt}$ for 45 minutes, and then (S)-3-amino-2,2-dimethyl-4-oxoazetidin-1-yl-hydrogen sulfate $12 \mathrm{a}(0.11 \mathrm{~g}, 0.52 \mathrm{mmol})$ was added followed by $\mathrm{NaHCO}_{3}(88.0 \mathrm{mg}, 1.05 \mathrm{mmol})$ addition. The reaction mixture was further stirred at $\mathrm{rt}$ for 16 hours. After the reaction completion, the solvent was removed under reduced pressure to afford a residue which was purified by flash chromatography on silica gel eluting by $5-10 \% \mathrm{MeOH}$ in $\mathrm{CH}_{2} \mathrm{Cl}_{2}$ to give the title compound $13 \mathrm{a}(0.32 \mathrm{~g}, 86 \%$ yield $)$ as a pale yellow solid. ${ }^{1} \mathrm{H}$ NMR $\left(400 \mathrm{MHz}, \mathrm{DMSO}-d_{6}\right): \delta 1.11(\mathrm{~s}, 3 \mathrm{H})$, $1.37(\mathrm{~s}, 3 \mathrm{H}), 1.41(\mathrm{~s}, 9 \mathrm{H}), 1.46(\mathrm{~s}, 9 \mathrm{H}), 1.44-1.51(\mathrm{~m}$, $2 \mathrm{H}), 1.87-1.97(\mathrm{~m}, 2 \mathrm{H}), 2.72-2.89(\mathrm{~m}, 2 \mathrm{H}), 3.78-3.88$ $(\mathrm{m}, 1 \mathrm{H}), 3.94-4.04(\mathrm{~m}, 2 \mathrm{H}), 4.45-4.52(\mathrm{~m}, 1 \mathrm{H}), 4.57(\mathrm{~d}$, $J=7.8 \mathrm{~Hz}, 1 \mathrm{H}), 4.58-4.65(\mathrm{~m}, 1 \mathrm{H}), 5.33-5.38(\mathrm{~m}, 1 \mathrm{H})$, $6.92(\mathrm{~s}, 1 \mathrm{H}), 7.07(\mathrm{~d}, J=8.8 \mathrm{~Hz}, 2 \mathrm{H}), 7.17-7.50(\mathrm{~m}$, $10 \mathrm{H}), 7.70(\mathrm{~d}, J=8.8 \mathrm{~Hz}, 2 \mathrm{H}), 8.98(\mathrm{~s}, 1 \mathrm{H}), 9.30(\mathrm{~s}, 1 \mathrm{H})$, $9.38(\mathrm{~d}, J=7.8 \mathrm{~Hz}, 1 \mathrm{H}), 9.63(\mathrm{~d}, J=7.8 \mathrm{~Hz}, 1 \mathrm{H}), 12.1$ (s,
1H). LC-MS $[\mathrm{M}-\mathrm{H}]^{-} m / z 1067.3$ and $[\mathrm{M}+2-\mathrm{H}]^{-} \mathrm{m} / z$ 1069.3 (calcd for $\mathrm{C}_{48} \mathrm{H}_{57} \mathrm{ClN}_{8} \mathrm{O}_{14} \mathrm{~S}_{2}, 1068.31$ )

14a: to the solution of compound $13 \mathrm{a}(0.32 \mathrm{~g}, 0.30 \mathrm{mmol})$ in anhydrous $\mathrm{CH}_{2} \mathrm{Cl}_{2}(4 \mathrm{~mL})$, TFA $(3 \mathrm{~mL})$ at $0^{\circ} \mathrm{C}$ was added. After stirring for 1 hour at $0^{\circ} \mathrm{C}$, the resulting mixture was warmed to $\mathrm{rt}$ and stirred for additional 2 hours. After completion of the reaction, the solvent was evaporated to give a residue which was dissolved in water $(20 \mathrm{~mL})$ and washed with petroleum ether/EtOAc $(2: 1$, $40 \mathrm{~mL})$. The aqueous layer was separated and freeze-dried to furnish the crude title compound $(0.28 \mathrm{~g})$ as a pale yellow powder, which was further purified by preparative HPLC on a Agilent 10 prep-C18 $250 \times 21.2 \mathrm{~mm}$ column and lyophilized to give the target $14 a$ (16 mg, $7.6 \%$ yield) as a white solid. ${ }^{1} \mathrm{H}$ NMR $\left(400 \mathrm{MHz}, \mathrm{DMSO}-d_{6}\right): \delta 1.29(\mathrm{~s}$, $3 \mathrm{H}), 1.42(\mathrm{~s}, 3 \mathrm{H}), 1.71-1.87(\mathrm{~m}, 2 \mathrm{H}), 1.98-2.12(\mathrm{~m}, 2 \mathrm{H})$, 2.81-2.96 (m, 3H), 3.80-3.91 (m, 2H), 4.37-4.53 (m, 2H), $4.69(\mathrm{~d}, J=8.8 \mathrm{~Hz}, 1 \mathrm{H}), 4.73(\mathrm{~d}, J=7.8 \mathrm{~Hz}, 1 \mathrm{H}), 7.20(\mathrm{~d}$, $J=8.2 \mathrm{~Hz}, 2 \mathrm{H}), 7.36$ (br s, $2 \mathrm{H}), 7.69$ (d, $J=8.2 \mathrm{~Hz}, 2 \mathrm{H})$, 8.99 (br s, $1 \mathrm{H}), 9.45$ (br s $1 \mathrm{H}), 9.63$ (br s, $1 \mathrm{H}), 11.6$ (d, $J=6.84 \mathrm{~Hz}, 1 \mathrm{H}) .{ }^{13} \mathrm{C} \mathrm{NMR}\left(100 \mathrm{MHz}, \mathrm{D}_{2} \mathrm{O}\right): \delta 19.6$ (s), 22.1 (s), 26.9 (s), 42.5 (s), 47.5 (s), $61.0(\mathrm{~s}), 68.0$ (s), 70.9 (s), 83.8 (s), 115.3 (s), 121.0 (s), 129.9 (s), 131.5 (s), 146.6 (s), 162.4 (s), 163.7 (s), 165.8 (s), 166.9 (s), 174.3 (s), 179.9 (s), 183.9 (s). LC-MS $[\mathrm{M}-\mathrm{H}]^{-} \mathrm{m} / z 701.1$ and $[\mathrm{M}+2-\mathrm{H}]^{-} \mathrm{m} / z 703.2$ (calcd for $\mathrm{C}_{25} \mathrm{H}_{31} \mathrm{ClN}_{8} \mathrm{O}_{10} \mathrm{~S}_{2}, 702.13$ ). HREIMS $m / z$ calcd for $\mathrm{C}_{25} \mathrm{H}_{31} \mathrm{ClN}_{8} \mathrm{O}_{10} \mathrm{~S}_{2}[\mathrm{M}-\mathrm{H}]^{-}$, 701.1215; found 701.1218.

14b: ${ }^{1} \mathrm{H}$ NMR $\left(400 \mathrm{MHz}, \mathrm{DMSO}-d_{6}\right): \delta 1.27$ (s, 3H), $1.41(\mathrm{~s}, 3 \mathrm{H}), 1.62-1.74(\mathrm{~m}, 2 \mathrm{H}), 1.87-2.02(\mathrm{~m}, 2 \mathrm{H})$, 2.82-2.92 (m, 2H), 3.04-3.12 (m, 2H), 3.82-3.93 (m, $1 \mathrm{H}), 4.18-4.26(\mathrm{~m}, 1 \mathrm{H}), 4.39-4.46(\mathrm{~m}, 1 \mathrm{H}), 4.69$ (d, 
$J=8.7 \mathrm{~Hz}, 1 \mathrm{H}), 4.74 \quad(\mathrm{~d}, J=5.5 \mathrm{~Hz}, 1 \mathrm{H}), 7.08 \quad(\mathrm{~d}$, $J=8.2 \mathrm{~Hz}, 2 \mathrm{H}), 7.36$ (br s, $2 \mathrm{H}), 7.62(\mathrm{~d}, J=8.2 \mathrm{~Hz}, 2 \mathrm{H})$, 9.29 (br s, $2 \mathrm{H}$ ), 10.63 (br s, $1 \mathrm{H}) .{ }^{13} \mathrm{C} \mathrm{NMR}(100 \mathrm{MHz}$, DMSO- $\left.d_{6}\right): \delta 20.6(\mathrm{~s}), 24.5(\mathrm{~s}), 26.9(\mathrm{~s}), 29.1(\mathrm{~s}), 44.7$ (s), 48.4 (s), 49.7 (s), 60.7 (s), 67.3 (s), 68.7 (s), 83.6 (s), 111.0 (s), 115.2 (s), 121.4 (s), 130.0 (s), 130.8 (s), 138.4 (s), 150.9 (s), 162.3 (s), 162.8 (s), 163.1 (s), 164.8 (s), 171.7 (s). LC-MS [M-H] $]^{-} m / z 700.9$ and $[\mathrm{M}+2-\mathrm{H}]^{-} \mathrm{m} / z$ 702.8 (calcd for $\mathrm{C}_{25} \mathrm{H}_{31} \mathrm{ClN}_{8} \mathrm{O}_{10} \mathrm{~S}_{2}, 702.13$ ). HREIMS $\mathrm{m} / z$ calcd for $\mathrm{C}_{25} \mathrm{H}_{31} \mathrm{ClN}_{8} \mathrm{O}_{10} \mathrm{~S}_{2}[\mathrm{M}-\mathrm{H}]^{-}, 701.1215$; found 701.1218.

14c: ${ }^{1} \mathrm{H}$ NMR (400 MHz, DMSO- $\left.d_{6}\right): \delta 1.26(\mathrm{~s}, 3 \mathrm{H}), 1.41$ $(\mathrm{s}, 3 \mathrm{H}), 1.54-1.79(\mathrm{~m}, 3 \mathrm{H}), 1.92-2.02(\mathrm{~m}, 1 \mathrm{H})$, 2.73-2.81 (m, 1H), 2.87-2.98 (m, 3H), 3.84-3.91 (m, $1 \mathrm{H}), 4.10-4.16(\mathrm{~m}, 1 \mathrm{H}), 4.35(\mathrm{t}, J=9.5 \mathrm{~Hz}, 1 \mathrm{H}), 4.67(\mathrm{~d}$, $J=8.8 \mathrm{~Hz}, 1 \mathrm{H}), 4.70(\mathrm{~d}, J=8.5 \mathrm{~Hz}, 1 \mathrm{H}), 7.13(\mathrm{~d}$, $J=8.5 \mathrm{~Hz}, 2 \mathrm{H}), 7.33$ (br s, $2 \mathrm{H}), 7.72(\mathrm{~d}, J=8.5 \mathrm{~Hz}, 2 \mathrm{H})$, 9.21 (br s, 3H), 11.08 (br s, 1H). LC-MS [M-H] $]^{-} \mathrm{m} / z$ 701.1 and $[\mathrm{M}+2-\mathrm{H}]^{-} \mathrm{m} / z \quad 703.1 \quad$ (calcd for $\mathrm{C}_{25} \mathrm{H}_{31} \mathrm{ClN}_{8} \mathrm{O}_{10} \mathrm{~S}_{2}$, 702.13). HREIMS $\mathrm{m} / z$ calcd for $\mathrm{C}_{25} \mathrm{H}_{31} \mathrm{ClN}_{8} \mathrm{O}_{10} \mathrm{~S}_{2}[\mathrm{M}-\mathrm{H}]^{-}$, 701.1215; found 701.1219.

14d: ${ }^{1} \mathrm{H}$ NMR $\left(400 \mathrm{MHz}, \mathrm{DMSO}-d_{6}\right): \delta 1.27(\mathrm{~s}, 3 \mathrm{H})$, $1.41(\mathrm{~s}, 3 \mathrm{H}), 2.00-2.09(\mathrm{~m}, 1 \mathrm{H}), 2.17-2.26(\mathrm{~m}, 1 \mathrm{H})$, 3.07-3.15 (m, 1H), 3.21-3.36 (m, 3H), 4.22-4.27 (m, $1 \mathrm{H}), 4.36-4.44(\mathrm{~m}, 2 \mathrm{H}), 4.65(\mathrm{t}, J=8.6 \mathrm{~Hz}, 1 \mathrm{H}), 4.72(\mathrm{~d}$, $J=8.5 \mathrm{~Hz}, 1 \mathrm{H}), 7.13(\mathrm{~d}, J=8.5 \mathrm{~Hz}, 2 \mathrm{H}), 7.35$ (br s, $2 \mathrm{H})$, $7.74(\mathrm{~d}, J=8.5 \mathrm{~Hz}, 2 \mathrm{H}), 8.30$ (br s, 3H), 10.35 (d, $J=8.6 \mathrm{~Hz}, 1 \mathrm{H})$. LC-MS $[\mathrm{M}-\mathrm{H}]^{-} m / z 687.1$ and $[\mathrm{M}+2-$ $\mathrm{H}]^{-} m / z 689.1$ (calcd for $\mathrm{C}_{24} \mathrm{H}_{29} \mathrm{ClN}_{8} \mathrm{O}_{10} \mathrm{~S}_{2}, 688.1$ ). HREIMS $m / z$ calcd for $\mathrm{C}_{24} \mathrm{H}_{29} \mathrm{ClN}_{8} \mathrm{O}_{10} \mathrm{~S}_{2}[\mathrm{M}-\mathrm{H}]^{-}$, 687.1058; found 687.1051.688.11.

14e: ${ }^{1} \mathrm{H}$ NMR $\left(400 \mathrm{MHz}, \mathrm{DMSO}-d_{6}\right): \delta 1.27(\mathrm{~s}, 3 \mathrm{H})$, $1.42(\mathrm{~s}, 3 \mathrm{H}), 2.14-2.27(\mathrm{~m}, 2 \mathrm{H}), 3.25-3.45(\mathrm{~m}, 3 \mathrm{H})$, $3.57-3.64(\mathrm{~m}, 1 \mathrm{H}), 4.16(\mathrm{~d}, J=9.7 \mathrm{~Hz}, 1 \mathrm{H}), 4.40(\mathrm{t}$, $J=9.7 \mathrm{~Hz}, 1 \mathrm{H}), 4.45-3.51(\mathrm{~m}, 1 \mathrm{H}), 4.63(\mathrm{~d}, J=8.4 \mathrm{~Hz}$, $1 \mathrm{H}), 4.77(\mathrm{~d}, J=8.7 \mathrm{~Hz}, 1 \mathrm{H}), 7.09(\mathrm{~d}, J=8.3 \mathrm{~Hz}, 2 \mathrm{H})$, 7.36 (br s, 2H), 7.75 (d, $J=8.3 \mathrm{~Hz}, 2 \mathrm{H}), 9.04$ (br s, 2H), 10.35 (br s, $1 \mathrm{H}) .{ }^{13} \mathrm{C} \mathrm{NMR}\left(100 \mathrm{MHz}, \mathrm{D}_{2} \mathrm{O}\right): \delta 19.6(\mathrm{~s})$, $22.1(\mathrm{~s}), 29.6(\mathrm{~s}), 44.4(\mathrm{~s}), 48.9$ (s), $51.7(\mathrm{~s}), 61.0$ (s), 67.9 (s), 70.8 (s), 85.3 (s), 115.2 (s), 120.5 (s), 130.1 (s), 146.5 (s), 159.9 (s), $161.2(\mathrm{~s}), 161.7$ (s), 163.6 (s), 164.1 (s), 167.2 (s), 174.4 (s), 183.9 (s). LC-MS [M-H] ${ }^{-} \mathrm{m} / z 686.9$ and $[\mathrm{M}+2-\mathrm{H}]^{-} m / z 688.9$ (calcd for $\mathrm{C}_{24} \mathrm{H}_{29} \mathrm{ClN}_{8} \mathrm{O}_{10} \mathrm{~S}_{2}$, 688.11). HREIMS $m / z$ calcd for $\mathrm{C}_{24} \mathrm{H}_{29} \mathrm{ClN}_{8} \mathrm{O}_{10} \mathrm{~S}_{2}$ [M$\mathrm{H}]^{-}, 687.1058$; found 687.1049 .

2.1.5. Synthesis of Compound $\mathbf{1 4 g}$. Synthesis of compound $\mathbf{1 4 g}$ was carried out according to Scheme 3. Compounds 11c and $\mathbf{1 2 b}$ were coupled according to the procedure described for $\mathbf{1 3 a}$ from the compound $\mathbf{1 3} \mathbf{g}$. Boc deprotection in $\mathbf{1 3} \mathbf{g}$ was accomplished using analogous procedure described for compound 14a to afford the final compound $14 \mathrm{~g}$ in $11 \%$ yield. ${ }^{1} \mathrm{H}$ NMR $\left(400 \mathrm{MHz}, \mathrm{DMSO}-d_{6}\right): \delta 1.35(\mathrm{~d}, J=6.4 \mathrm{~Hz}$, $3 \mathrm{H}), 1.42-1.49(\mathrm{~m}, 1 \mathrm{H}), 1.63-1.71(\mathrm{~m}, 1 \mathrm{H}), 1.79-1.87(\mathrm{~m}$, $1 \mathrm{H}), 1.95-2.02(\mathrm{~m}, 1 \mathrm{H}), 2.86-2.95(\mathrm{~m}, 1 \mathrm{H}), 2.98-3.08(\mathrm{~m}$, $3 \mathrm{H}), 3.60-3.65(\mathrm{~m}, 1 \mathrm{H}), 3.91-3.97(\mathrm{~m}, 1 \mathrm{H}), 4.13-4.19(\mathrm{~m}$, $1 \mathrm{H}), 4.30(\mathrm{t}, J=8.6 \mathrm{~Hz}, 1 \mathrm{H}), 4.42(\mathrm{dd}, J=7.9,2.6 \mathrm{~Hz}, 1 \mathrm{H})$, $4.72(\mathrm{~d}, J=7.4 \mathrm{~Hz}, 1 \mathrm{H}), 6.65$ (br s, $1 \mathrm{H}), 7.14$ (d, $J=8.7 \mathrm{~Hz}$, 2H), 7.19 (br s, 2H), $7.72(\mathrm{~d}, J=8.7 \mathrm{~Hz}, 2 \mathrm{H}) .{ }^{13} \mathrm{C} \mathrm{NMR}$ $\left(100 \mathrm{MHz}, \mathrm{D}_{2} \mathrm{O}\right): \delta 16.6(\mathrm{~s}), 23.7(\mathrm{~s}), 24.9(\mathrm{~s}), 42.5(\mathrm{~s}), 45.9(\mathrm{~s})$, 49.7 (s), 61.0 (s), $63.1(\mathrm{~s}), 66.3(\mathrm{~s}), 79.3(\mathrm{~s}), 100.7(\mathrm{~s}), 114.6(\mathrm{~s})$, 120.3 (s), 119.0 (s), 130.1 (s), 144.0 (s), 158.1 (s), 160.1 (s), 163.5 (s), 172.0 (s), 175.0 (s), 185.2 (s). LC-MS [M-H] ${ }^{-} \mathrm{m} / z$ 671.1 and $[\mathrm{M}+2-\mathrm{H}]^{-} \mathrm{m} / z 673.1$ (calcd for $\mathrm{C}_{24} \mathrm{H}_{29} \mathrm{ClN}_{8} \mathrm{O}_{10} \mathrm{~S}_{2}$, 672.12). HREIMS $m / z$ calcd for $\mathrm{C}_{24} \mathrm{H}_{29} \mathrm{ClN}_{8} \mathrm{O}_{9} \mathrm{~S}_{2}[\mathrm{M}-\mathrm{H}]^{-}$, 672.1187; found 672.1181.

2.1.6. Synthesis of Compounds 18a, 18b, and 18d-f. Compounds 18a, 18b, and 18d-f were synthesized according to Scheme 4 using general procedures described for a representative compound for each step as follows:

16a: 2-(5-((tert-butoxycarbonyl)amino)-1,2,4-thiadiazol-3-yl)-2-oxoacetic acid $15(0.27 \mathrm{~g}, 1.0 \mathrm{mmol})$ [17] was added to the solution of compound $9 \mathrm{a}(0.235 \mathrm{~g}$, $0.4 \mathrm{mmol})$ in ethanol $(3 \mathrm{~mL})$ and chloroform $(3 \mathrm{~mL})$. Afterward, the reaction mixture was stirred at $\mathrm{rt}$ for 18 hours followed by the concentration of the solvent under vacuo and purification of the crude product by flash column chromatography using $10-20 \% \mathrm{MeOH}$ in $\mathrm{CH}_{2} \mathrm{Cl}_{2}$ as solvent. The title compound $\mathbf{1 6 a}(88 \mathrm{mg}, 26 \%$ yield) was obtained as pale yellow solid. ${ }^{1} \mathrm{H} \mathrm{NMR}$ $\left(400 \mathrm{MHz}, \mathrm{DMSO}-d_{6}\right): \delta 1.40(\mathrm{~s}, 9 \mathrm{H}), 1.49(\mathrm{~s}, 9 \mathrm{H})$, $1.82-1.98(\mathrm{~m}, 3 \mathrm{H}), 2.81(\mathrm{~s}, 2 \mathrm{H}), 3.88(\mathrm{~s}, 2 \mathrm{H}), 3.98(\mathrm{~s}$, $2 \mathrm{H}), 4.46-4.58(\mathrm{~m}, 2 \mathrm{H}), 5.16(\mathrm{~s}, 1 \mathrm{H}), 6.88(\mathrm{~s}, 1 \mathrm{H}), 7.10$ $(\mathrm{d}, J=8.7 \mathrm{~Hz}, 2 \mathrm{H}), 7.14-7.45(\mathrm{~m}, 10 \mathrm{H}), 7.49(\mathrm{~d}$, $J=7.3 \mathrm{~Hz}, 2 \mathrm{H}), 7.68(\mathrm{~d}, J=8.7 \mathrm{~Hz}, 2 \mathrm{H}), 9.12(\mathrm{~s}, 1 \mathrm{H})$, $9.38(\mathrm{~s}, 1 \mathrm{H}), 9.45(\mathrm{~s}, 1 \mathrm{H})$. LC-MS $[\mathrm{M}+\mathrm{H}]^{+} \mathrm{m} / z 844.3$ (calcd for $\mathrm{C}_{42} \mathrm{H}_{49} \mathrm{~N}_{7} \mathrm{O}_{10} \mathrm{~S}, 843.33$ ).

17a: to the solution of compound 16a (0.179 g, $0.22 \mathrm{mmol})$ in anhydrous DMF $(3.5 \mathrm{~mL}), \mathrm{DCC}(68 \mathrm{mg}$, $0.33 \mathrm{mmol})$ and HOBT $(0.045 \mathrm{~g}, 0.33 \mathrm{mmol})$ were added. The reaction mixture was stirred at $\mathrm{rt}$ for 45 minutes. $(S)$ 3-amino-2,2-dimethyl-4-oxoazetidin-1-ylhydrogen sulfate $12 \mathrm{a}$ (69 mg, $0.33 \mathrm{mmol}$ ) and $\mathrm{NaHCO}_{3}(55 \mathrm{mg}$, $0.66 \mathrm{mmol}$ ) were then added, and the reaction mixture was stirred at $\mathrm{rt}$ for $16 \mathrm{~h}$. After completion, the reaction mixture was concentrated in vacuo to give crude product which was purified by flash chromatography on silica gel using $5-10 \% \mathrm{MeOH}$ in $\mathrm{CH}_{2} \mathrm{Cl}_{2}$ as solvent. The desire compound 17a (98 mg, 44\%) was obtained as pale yellow solid. ${ }^{1} \mathrm{H}$ NMR (400 MHz, DMSO- $\left.d_{6}\right): \delta 1.09(\mathrm{~s}, 3 \mathrm{H})$, 1.23 (s, 3H), 1.39 (s, 9H), 1.50 (s, 9H), 4.01 (s, 2H), 4.12 (s, 2H), $4.22(\mathrm{~s}, 2 \mathrm{H}), 4.50(\mathrm{~s}, 1 \mathrm{H}), 4.62(\mathrm{~s}, 1 \mathrm{H}), 5.49$ (s, $1 \mathrm{H}), 6.92(\mathrm{~s}, 1 \mathrm{H}), 7.08(\mathrm{~d}, J=8.5 \mathrm{~Hz}, 2 \mathrm{H}), 7.13-7.38(\mathrm{~m}$, $10 \mathrm{H}), 7.48(\mathrm{~d}, J=7.1 \mathrm{~Hz}, 2 \mathrm{H}), 7.63(\mathrm{~s}, 1 \mathrm{H}), 7.76(\mathrm{~d}$, $J=8.5 \mathrm{~Hz}, 2 \mathrm{H}), 7.90$ (s, 1H), 8.91 (s, 1H), 9.45 (s, 1H), 9.67 (s, 1H). LC-MS [M-H] $]^{-} \mathrm{m} / z 1034.3$ (calcd for $\left.\mathrm{C}_{47} \mathrm{H}_{57} \mathrm{~N}_{9} \mathrm{O}_{14} \mathrm{~S}_{2}, 1035.35\right)$.

18a: a solution of compound $17 \mathbf{a}(80 \mathrm{mg}, 0.077 \mathrm{mmol})$ in anhydrous $\mathrm{CH}_{2} \mathrm{Cl}_{2}(2 \mathrm{~mL})$ was added with TFA $(2 \mathrm{~mL})$ at $0^{\circ} \mathrm{C}$. After stirring for 1 hour at $0^{\circ} \mathrm{C}$, the reaction mixture was warmed to $\mathrm{rt}$ slowly and stirred for additional 3 hours. Subsequently, the reaction mixture was concentrated, and the residue was 

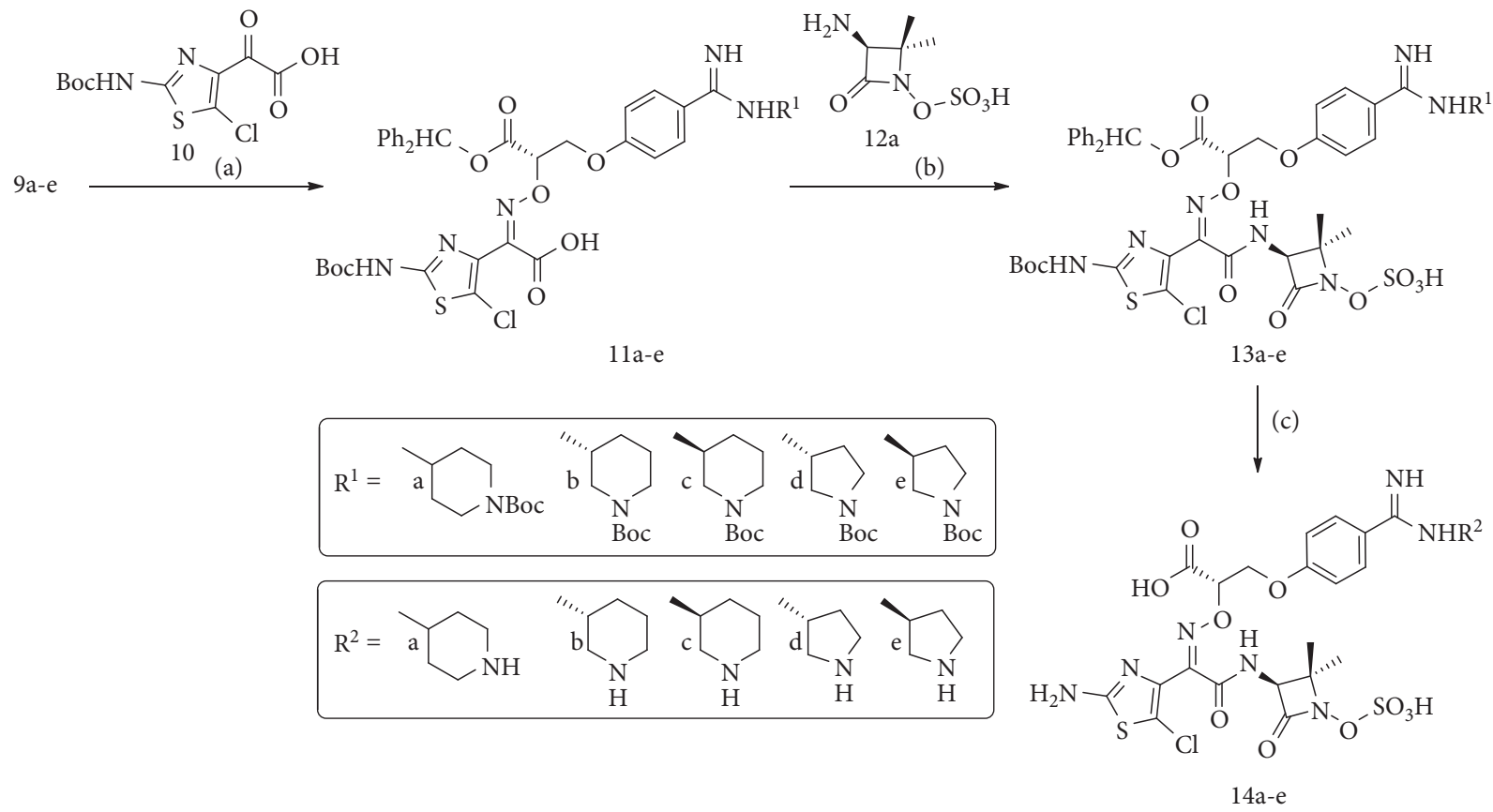

Scheme 2: Synthesis of compounds 14a-e. Reagents and conditions: (a) 10, EtOH-CHCl 3, rt, 71-87\%; (b) 12a, $\mathrm{HOBT}, \mathrm{DCC}, \mathrm{NaHCO}$, DMF, $0^{\circ} \mathrm{C}-\mathrm{rt}, 41-88 \%$; (c) $\mathrm{TFA}, \mathrm{CH}_{2} \mathrm{Cl}_{2}, 0^{\circ} \mathrm{C}-\mathrm{rt}, 7-15 \%$.
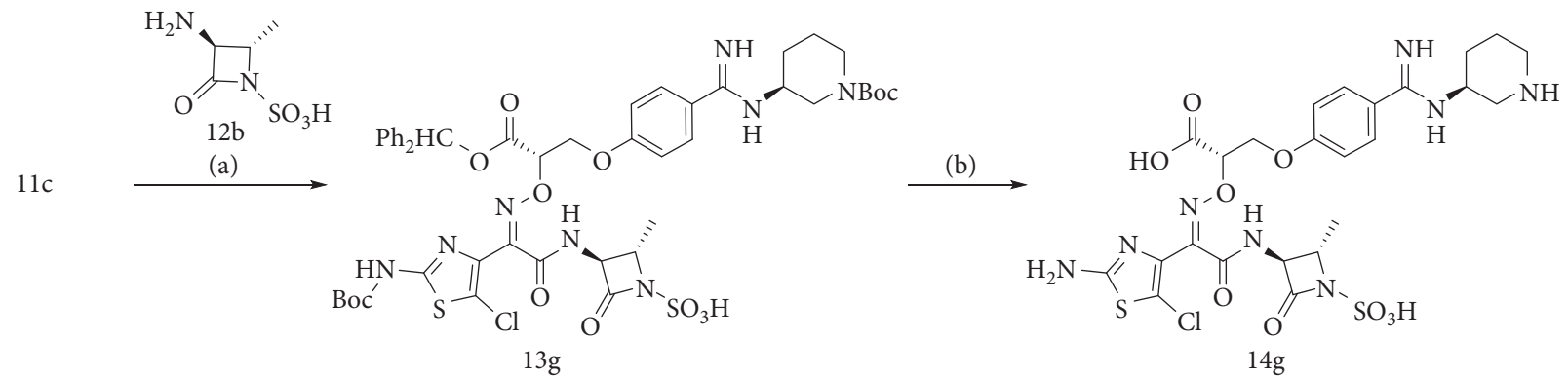

Scheme 3: Synthesis of compound 14g. Reagents and conditions: (a) 12a, $\mathrm{HOBT}, \mathrm{DCC}, \mathrm{NaHCO}_{3}, \mathrm{DMF}, 0^{\circ} \mathrm{C}-\mathrm{rt}, 69 \%$; (b) $\mathrm{TFA}, \mathrm{CH}_{2} \mathrm{Cl}_{2}, 0^{\circ} \mathrm{C}$ - rt, $11 \%$.

dissolved in water $(10 \mathrm{~mL})$ and washed with petroleum ether/EtOAc $(2: 1,30 \mathrm{~mL})$. The aqueous layer was freeze-dried to give the crude title compound $(70 \mathrm{mg}$ ) as a pale yellow powder, which was purified by preparative HPLC on Agilent 10 prep-C18 $250 \times 21.2 \mathrm{~mm}$ column and lyophilized to give the title compound 18a (15 mg, $29.1 \%$ yield) as a white solid. ${ }^{1} \mathrm{H}$ NMR $\left(400 \mathrm{MHz}, \mathrm{DMSO}-d_{6}\right): \delta 1.23(\mathrm{~s}, 3 \mathrm{H}), 1.41(\mathrm{~s}, 3 \mathrm{H})$, 1.71-1.85 (m, 2H), 2.01-2.09 (m, 2H), 2.81-2.93 (m, 3 $\mathrm{H}), 3.79-3.88(\mathrm{~m}, 2 \mathrm{H}), 4.36-4.50(\mathrm{~m}, 2 \mathrm{H}), 4.67(\mathrm{~d}$, $J=8.4 \mathrm{~Hz}, 1 \mathrm{H}), 4.76(\mathrm{~d}, J=6.9 \mathrm{~Hz}, 1 \mathrm{H}), 7.21 \quad(\mathrm{~d}$, $J=7.1 \mathrm{~Hz}, 2 \mathrm{H}), 7.70$ (d, $J=7.1 \mathrm{~Hz}, 2 \mathrm{H}), 8.14$ (br s, $1 \mathrm{H})$, 8.17 (br s, $1 \mathrm{H}$ ), 8.99 (br s, $1 \mathrm{H}), 9.43$ (br s, $1 \mathrm{H}$ ), 9.67 (br s, $1 \mathrm{H}), 11.02$ (br s, $1 \mathrm{H}) .{ }^{13} \mathrm{C} \mathrm{NMR}\left(100 \mathrm{MHz}, \mathrm{D}_{2} \mathrm{O}\right): \delta 19.6$ (s), 22.1 (s), 26.9 (s), 42.5 (s), 47.6 (s), 60.9 (s), 67.9 (s), 70.9 (s), 83.9 (s), 115.3 (s), 121.0 (s), 129.9 (s), 146.9 (s), 160.8 (s), $162.4(\mathrm{~s}), 163.4(\mathrm{~s}), 163.5$ (s), $163.6(\mathrm{~s}), 174.6$ (s), 184.4 (s). LC-MS [M-H] ${ }^{-} \mathrm{m} / z 667.9$ (calcd for $\mathrm{C}_{24} \mathrm{H}_{31} \mathrm{~N}_{9} \mathrm{O}_{10} \mathrm{~S}_{2}$, 669.16). HREIMS $\mathrm{m} / z$ calcd for $\mathrm{C}_{24} \mathrm{H}_{31} \mathrm{~N}_{9} \mathrm{O}_{10} \mathrm{~S}_{2}[\mathrm{M}-\mathrm{H}]^{-}$, 668.1557; found 668.1550. 18b: ${ }^{1} \mathrm{H}$ NMR $\left(400 \mathrm{MHz}, \mathrm{DMSO}-d_{6}\right): \delta 1.21(\mathrm{~s}, 3 \mathrm{H})$, $1.40(\mathrm{~s}, 3 \mathrm{H}), 1.69-1.79(\mathrm{~m}, 2 \mathrm{H}), 1.94-2.04(\mathrm{~m}, 2 \mathrm{H})$, 2.87-3.01 (m, 2H), 3.11-3.19 (m, 2H), 3.84-3.92 (m, $1 \mathrm{H}), 4.16-4.23(\mathrm{~m}, 1 \mathrm{H}), 4.41-4.47(\mathrm{~m}, 1 \mathrm{H}), 4.66(\mathrm{~d}$, $J=8.1 \mathrm{~Hz}, 1 \mathrm{H}), 4.78-4.82(\mathrm{~m}, 1 \mathrm{H}), 7.02(\mathrm{~d}, J=8.6 \mathrm{~Hz}$, $2 \mathrm{H}), 7.59$ (d, $J=8.6 \mathrm{~Hz}, 2 \mathrm{H}), 8.14$ (br s, $2 \mathrm{H}), 9.02$ (br s, $1 \mathrm{H}), 9.23$ (br s, $1 \mathrm{H}), 11.04$ (br s, $1 \mathrm{H}),{ }^{13} \mathrm{C} \mathrm{NMR}$ $\left(100 \mathrm{MHz}, \mathrm{D}_{2} \mathrm{O}\right): \delta 19.6$ (s), 20.1 (s), 22.1 (s), 26.9 (s), $43.4(\mathrm{~s}), 45.1$ (s), 46.9 (s), 60.9 (s), 67.9 (s), 70.9 (s), 83.9 (s), 115.3 (s), 120.7 (s), 130.0 (s), 146.9 (s), 160.7 (s), 162.5 (s), 163.5 (s), 163.6 (s), 163.8 (s), 167.2 (s), 174.6 (s), 184.4 (s). LC-MS [M-H] ${ }^{-} m / z 667.9$ (calcd for $\mathrm{C}_{24} \mathrm{H}_{31} \mathrm{~N}_{9} \mathrm{O}_{10} \mathrm{~S}_{2}$, 669.16). HREIMS $\mathrm{m} / z$ calcd for $\mathrm{C}_{24} \mathrm{H}_{31} \mathrm{~N}_{9} \mathrm{O}_{10} \mathrm{~S}_{2}[\mathrm{M}-\mathrm{H}]^{-}, 668.1557$; found 668.1563.

18d: ${ }^{1} \mathrm{H}$ NMR (400 MHz, DMSO- $\left.d_{6}\right): \delta 1.26$ (s, 3H), 1.43 (s, 3H), 1.98-2.03 (m, 1H), 2.07-2.15 (m, 1H), 3.27-3.34 $(\mathrm{m}, 1 \mathrm{H}), 3.35-3.45(\mathrm{~m}, 2 \mathrm{H}), 3.46-3.54(\mathrm{~m}, 1 \mathrm{H})$, $4.16-4.21(\mathrm{~m}, 1 \mathrm{H}), 4.40-4.45(\mathrm{~m}, 2 \mathrm{H}), 4.69(\mathrm{~d}, J=8.7 \mathrm{~Hz}$, $1 \mathrm{H}), 4.72(\mathrm{t}, J=4.9 \mathrm{~Hz}, 1 \mathrm{H}), 7.18(\mathrm{~d}, J=8.7 \mathrm{~Hz}, 2 \mathrm{H}), 7.72$ (d, $J=8.7 \mathrm{~Hz}, 2 \mathrm{H}$ ), 8.12 (br s, $2 \mathrm{H}$ ), 8.41 (br s, $5 \mathrm{H}$ ), 11.25 


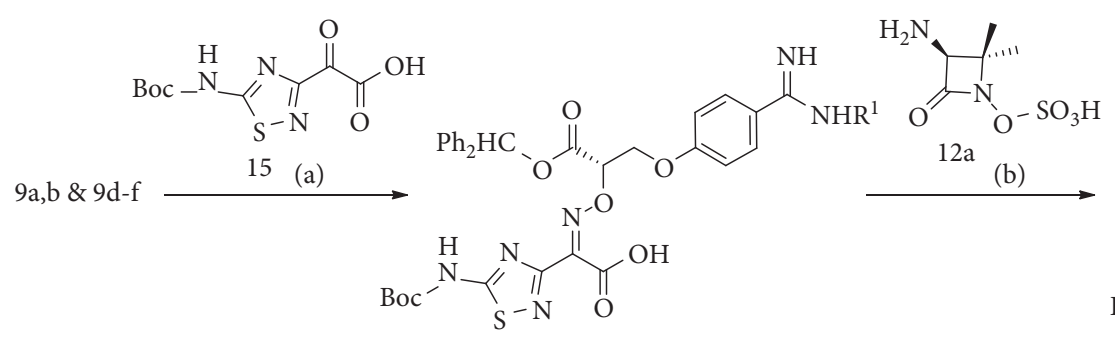

$16 a, b$ \& $16 d-f$
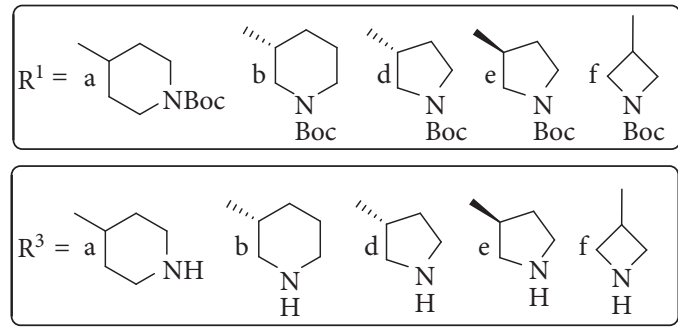<smiles>CNC(=N)c1ccc(OCC(OOC(=O)C(=N)c2nsc(NC(=O)c3ccccc3)n2)C(=O)NC2C(=O)N(OO)C2(C)C)cc1</smiles>

$17 \mathrm{a}, \mathrm{b} \& 17 \mathrm{~d}-\mathrm{f}$<smiles>[R1]NC(=N)c1ccc(OC[C@H](O/N=C(\C(=O)N[C@H]2C(=O)N(OS(=O)(=O)O)C2(C)C)c2nsc(N)n2)C(=O)O)cc1</smiles>

$18 \mathrm{a}, \mathrm{b} \& \mathrm{\alpha} 18 \mathrm{~d}-\mathrm{f}$

SCHeme 4: Synthesis of compounds 18a,b and 18d-f. Reagents and conditions: (a) 15, EtOH-CHCl ${ }_{3}, \mathrm{rt}, 26-60 \%$; (b) 12a, HOBT, DCC, $\mathrm{NaHCO}_{3}$, DMF, $0^{\circ} \mathrm{C}-\mathrm{rt}, 41-84 \%$; (c) TFA, $\mathrm{CH}_{2} \mathrm{Cl}_{2}, 0^{\circ} \mathrm{C}-\mathrm{rt}, 12-29 \%$.

(br s, $1 \mathrm{H}) .{ }^{13} \mathrm{C}$ NMR $\left(100 \mathrm{MHz}, \mathrm{D}_{2} \mathrm{O}\right): \delta 19.6$ (s), 22.1 (s), $29.6(\mathrm{~s}), 44.3(\mathrm{~s}), 49.0(\mathrm{~s}), 51.7(\mathrm{~s}), 60.9(\mathrm{~s}), 68.0$ (s), 70.9 (s), 84.2 (s), $115.3(\mathrm{~s}), 118.2(\mathrm{~s}), 129.9(\mathrm{~s}), 152.8(\mathrm{~s}), 162.6$ (s), 162.9 (s), $163.8(\mathrm{~s}), 164.0(\mathrm{~s}), 169.0(\mathrm{~s}), 171.1(\mathrm{~s}), 184.4$ (s). LC-MS [M-H] $]^{-} m / z 654.2$ (calcd for $\mathrm{C}_{23} \mathrm{H}_{29} \mathrm{~N}_{9} \mathrm{O}_{10} \mathrm{~S}_{2}$, 655.15). HREIMS $m / z$ calcd for $\mathrm{C}_{23} \mathrm{H}_{29} \mathrm{~N}_{9} \mathrm{O}_{10} \mathrm{~S}_{2}[\mathrm{M}-\mathrm{H}]^{-}$, 654.1401; found 654.1409.

18e: ${ }^{1} \mathrm{H}$ NMR (400 MHz, DMSO- $\left.d_{6}\right): \delta 1.19(\mathrm{~s}, 3 \mathrm{H}), 1.40$ (s, 3H), 2.04-2.23 (m, 2H), 3.37-3.42 (m, 3H), 3.57-3.63 (m, 1H), 4.19-4.26 (m, 1H), 4.30-4.44 (m, 2H), 4.63 (d, $J=8.4 \mathrm{~Hz}, 1 \mathrm{H}), 4.76(\mathrm{~d}, J=7.8 \mathrm{~Hz}, 1 \mathrm{H}), 7.11 \quad(\mathrm{~d}$, $J=7.8 \mathrm{~Hz}, 2 \mathrm{H}), 7.74(\mathrm{~d}, J=7.8 \mathrm{~Hz}, 2 \mathrm{H}), 8.23$ (br s, $2 \mathrm{H}$ ), $10.35(\mathrm{~d}, J=8.4 \mathrm{~Hz}, 1 \mathrm{H}) .{ }^{13} \mathrm{C}$ NMR $\left(100 \mathrm{MHz}, \mathrm{D}_{2} \mathrm{O}\right): \delta$ 19.5 (s), 22.2 (s), 29.6 (s), 44.4 (s), 48.9 (s), 51.7 (s), 60.9 $(\mathrm{s}), 68.0(\mathrm{~s}), 70.9(\mathrm{~s}), 84.2(\mathrm{~s}), 115.3(\mathrm{~s}), 120.6(\mathrm{~s}), 130.1(\mathrm{~s})$, 146.8 (s), 162.6 (s), 162.7 (s), 163.0 (s), 163.6 (s), 168.9 (s), 175.0 (s), 184.5 (s). LC-MS [M-H] $]^{-} \mathrm{m} / z 654.2$ (calcd for $\mathrm{C}_{23} \mathrm{H}_{29} \mathrm{~N}_{9} \mathrm{O}_{10} \mathrm{~S}_{2}$, 655.15). HREIMS $\mathrm{m} / z$ calcd for $\mathrm{C}_{23} \mathrm{H}_{29} \mathrm{~N}_{9} \mathrm{O}_{10} \mathrm{~S}_{2}[\mathrm{M}-\mathrm{H}]^{-}$, 654.1401; found 654.1407.

18f: ${ }^{1} \mathrm{H}$ NMR (400 MHz, DMSO- $\left.d_{6}\right): \delta 1.15$ (s, 3H), 1.37 $(\mathrm{s}, 3 \mathrm{H}), 4.01-4.09(\mathrm{~m}, 2 \mathrm{H}), 4.16-4.26(\mathrm{~m}, 2 \mathrm{H})$, 4.29-4.39 (m, 2H), 4.55-4.64 (m, 2H), 4.78-4.86 (m, $1 \mathrm{H}), 7.04(\mathrm{~d}, J=8.6 \mathrm{~Hz}, 2 \mathrm{H}), 7.77(\mathrm{~d}, J=8.6 \mathrm{~Hz}, 2 \mathrm{H})$, 8.14 (br s, $2 \mathrm{H}), 10.20(\mathrm{~m}, 1 \mathrm{H}) .{ }^{13} \mathrm{C}$ NMR $(100 \mathrm{MHz}$, $\left.\mathrm{D}_{2} \mathrm{O}\right): \delta 19.9(\mathrm{~s}), 22.2(\mathrm{~s}), 46.6(\mathrm{~s}), 51.7(\mathrm{~s}), 60.9(\mathrm{~s}), 71.0$ (s), $72.3(\mathrm{~s}), 84.2(\mathrm{~s}), 115.3(\mathrm{~s}), 120.2(\mathrm{~s}), 130.2(\mathrm{~s}), 148.2$ (s), 160.7 (s), 158.7 (s), 161.7 (s), 163.7 (s), 169.9 (s), 175.0 (s), 183.0 (s). LC-MS [M-H] ${ }^{-} \mathrm{m} / z 640.7$ (calcd for $\mathrm{C}_{22} \mathrm{H}_{27} \mathrm{~N}_{9} \mathrm{O}_{10} \mathrm{~S}_{2}$, 641.13). HREIMS $\mathrm{m} / z$ calcd for $\mathrm{C}_{22} \mathrm{H}_{27} \mathrm{~N}_{9} \mathrm{O}_{10} \mathrm{~S}_{2}[\mathrm{M}-\mathrm{H}]^{-}$, 640.1244; found 640.1251 .

\subsection{Antibacterial Studies}

2.2.1. Acquisition of Bacterial Strains. Five type bacterial strains, namely, E. coli 8739 (CTX-M15), K. pneumoniae 700603 (KPC-3, TEM-1), E. cloacae 700323 (AmpC), A. baumannii 19606 (OXA-24), and P. aeruginosa 9027 (AmpC), containing different $\beta$-lactamase/s (indicated in parenthesis) were purchased from China Pharmaceutical Culture Collection (CPCC), whereas five species of clinical isolates such as $E$. coli clinical isolate (TEM-1), K. pneumoniae clinical isolate (SHV-1), E. cloacae clinical isolate (P99), A. baumannii clinical isolate (OXA-23/40), and $P$. aeruginosa clinical isolate (KPC-2) containing different $\beta$-lactamases were indigenously isolated and cultured from patients at Ningxia Medical University Hospital, P.R. China.

2.2.2. Antibacterial Assay. Synthesized compounds $\mathbf{1 4}$ and 18 were analyzed for their antibacterial activity using the broth microdilution method, and the results are presented as minimum inhibitory concentrations (MICs, in $\mu \mathrm{g} / \mathrm{mL}$ ) for each compound and references. The MIC values were measured according to the guidelines of the Clinical Laboratories and Standards Institute [18]. As a typical example, 14a was dissolved in DMSO and diluted, twofold in serial, with microbial growth medium (Mueller Hinton Broth II, cation adjusted) to reach the final concentration in a range of $0.063-64 \mu \mathrm{g} / \mathrm{mL}$. The final DMSO concentration was kept at less than $0.5 \%$ in each sample. At this stage, bacteria $\left(5 \times 10^{5}\right.$ colony-forming units/mL $(\mathrm{CFU} / \mathrm{mL})$ ) were added to each 
concentration of the test compound in a 96-well plate. The microtiter well plate was then incubated at $37^{\circ} \mathrm{C}$ for $18-24$ hours followed by their observation of MIC values by the naked eye (visually). Aztreonam and ceftazidime were used as the reference compounds in the same range of concentrations as the synthesized monobactams 14 and 18. Each compound and reference compounds were tested in triplicate for each concentration.

\section{Results and Discussion}

3.1. Synthesis of Intermediates $9 a-f$. The synthesis of compounds 9a-f (Scheme 1) started from ring opening of methyl $(R)$-oxirane-2-carboxylate by commercially available 4cyanophenol (1) catalyzed by (salen)Co(III) complex [19, 20] in tert-butylmethylether (TBME) at room temperature to form $\alpha$-hydroxyester 2 in $81 \%$ yield following the procedure described in the literature [21]. Later, the cyano group in compound 2 was reacted with methanolic $\mathrm{HCl}$ to generate the intermediate 3 as $\mathrm{HCl}$ salt in excellent yield. Compound $\mathbf{3}$ was then converted to amidines $\mathbf{5 a}-\mathbf{f}$ through nucleophilic substitution with appropriate amines $\left(\mathrm{H}_{2} \mathrm{~N}-\mathrm{R}_{\mathrm{a}-\mathrm{f}}\right)$ in the presence of trimethylamine. Base catalyzed hydrolysis of ester group in compounds $\mathbf{5 a - f}$ afforded the respective $\alpha$-hydroxy acids $\mathbf{6 a}-\mathbf{f}$. The carboxyl group in compounds 6a-f was then protected by reacting with diazo(diphenyl) methane $\left(\mathrm{Ph}_{2} \mathrm{CN}_{2}\right)$ to afford the corresponding derivatives 7a-f. Phthalimido derivatives $\mathbf{8 a - f}$ were obtained by reacting hydroxyl groups in compounds $7 \mathbf{a}-\mathbf{f}$ under Mitsunobu conditions using $N$-hydroxyphthalimide (PhthN$\mathrm{OH}$ ) in the presence of diethyl azodicarboxylate (DEAD) and triphenylphosphine $\left(\mathrm{PPh}_{3}\right)$ at room temperature. The conversion of phthalimido derivatives into the corresponding aminooxy compounds $\mathbf{9 a - f}$ was accomplished by the reaction of $\mathbf{8 a}-\mathbf{f}$ with hydrazine hydrate in good to excellent yields.

\subsection{Synthesis of Final Target Compounds. Compounds 9a-e} prepared in Scheme 1 were coupled with compound 10 [22] in a solvent mixture of ethanol and chloroform at room temperature to furnish intermediates 11a-e. The compounds $11 \mathbf{a}-\mathbf{e}$ were then reacted individually with compound 12a [23] to yield the corresponding compounds 13a-e. This coupling was achieved by $N$-hydroxybenzotriazole (HOBT) mediated activation of carboxyl group in compounds 13a-e followed by the removal of water by dicyclohexylcarbodiimide (DCC).

Subsequently, deprotection of the Boc and the diphenylmethyl groups in 13a-e was accomplished in one step by trifluoroacetic acid (TFA) in $\mathrm{CH}_{2} \mathrm{Cl}_{2}$ at room temperature in 2 hours. The resulting compounds $14 a-e$ were purified by preparative HPLC followed by the lyophilization to afford the final compounds as solids.

Compound 14g was prepared to start from 11c and coupling it with 12b [23] under HOBt/DCC activation to afford $13 \mathrm{~g}$ in $69.3 \%$ yield after purification. $13 \mathrm{~g}$ was then deprotected using the aforementioned reaction conditions to get the final compound $\mathbf{1 4} \mathbf{g}$ in $11.1 \%$ yield (Scheme 3 ).
Following Scheme 4, compounds 9a,b and 9d-f were also reacted with thiadiazole $15[22,23]$ to afford the compounds 16a,b and 16d-f, which were converted into final compounds $\mathbf{1 8 a}, \mathbf{b}$ and $\mathbf{1 8 d}-\mathbf{f}$ following the procedures described for $14 a-e$.

3.3. In Vitro Antimicrobial Activity. All the synthesized compounds $14 \mathbf{a}-\mathbf{e}, 14 \mathrm{~g}, 18 \mathbf{a}, \mathbf{b}$, and $18 \mathrm{~d}-\mathbf{f}$ were tested in vitro for their antibacterial activities against ten bacterial species, i.e., E. coli clinical isolate, E. coli 8739, K. pneumoniae clinical isolate, K. pneumoniae 700603, E. cloacae clinical isolate, E. cloacae 700323, A. baumannii clinical isolate, A. baumannii 19606, P. aeruginosa clinical isolate, and $P$. aeruginosa 9027, using broth microdilution method according to the guidelines of Clinical Laboratories and Standards Institute [18]. Minimum inhibitory concentration (MIC) for each compound was determined compared to aztreonam and ceftazidime as two reference antibiotics and is noted in Table 1. Aztreonam showed variable potencies against different strains with MIC values ranging from $16 \mu \mathrm{g} / \mathrm{mL}$ to $>64 \mu \mathrm{g} / \mathrm{mL}$ in contrast to ceftazidime which did not prove to be potent against these strains showing MIC value $>64 \mu \mathrm{g} / \mathrm{mL}$ for all tested strains.

As evident from the data reported in Table 1, all newly synthesized compounds showed variable degrees of potency against all tested bacterial strains. Compounds 14a-e, having variable $\mathrm{R}^{2}$-groups, showed MIC values ranging from 0.25 to $64 \mu \mathrm{g} / \mathrm{mL}$. Observing individual data of compounds 14, it can be observed that the compounds $14 d$ and 14e showed the highest potency against all tested strains with MIC values ranging from 0.25 to $8 \mu \mathrm{g} / \mathrm{mL}$. E. coli 8739 was the most susceptible strain toward compound $14 \mathbf{d}$, whereas 14e showed the highest potency against both $E$. coli strains with a MIC value of $0.25 \mu \mathrm{g} / \mathrm{mL}$. Furthermore, it can be ascertained that $A$. baumannii clinical isolate exhibited the highest resistance (MIC $8 \mu \mathrm{g} / \mathrm{mL}$ ) against 14e, whereas both strains of A. baumannii showed the highest level of resistance against the compound 14d.

Compound $14 \mathrm{~g}$ exhibited antibiotic potency with MIC values ranging from 0.5 to $64 \mu \mathrm{g} / \mathrm{mL}$. Compounds $14 \mathrm{c}$ and $\mathbf{1 4 g}$ are structurally similar with a slight difference; $\mathrm{C} 4$ of the azetidinone ring of $\mathbf{1 4 c}$ is substituted with dimethyl instead of monomethyl and $\mathrm{N} 1$ position is linked with $\mathrm{OSO}_{3} \mathrm{H}$ instead of $\mathrm{SO}_{3} \mathrm{H}$ group. Comparing the activities of these two compounds, it is evident that the antibacterial efficacy of $\mathbf{1 4 \mathbf { g }}$ is slightly compromised against most of the strains. This may be attributed to the structural variation of these two compounds at N1 and C4 positions resulting in the geometric orientation of $14 \mathrm{c}$ in a way that makes it more stable and hence better interaction and activity.

The antibacterial potency of compounds 18, which possess thiadiazole moiety instead of thiazole in contrast to its counterparts 14, varies from MIC values of $0.125 \mu \mathrm{g} / \mathrm{mL}$ to $64 \mu \mathrm{g} / \mathrm{mL}$. Among these, compounds $\mathbf{1 8 e}$ and $\mathbf{1 8 f}$ showed the highest potency against E. Coli 8739 and E. Coli clinical isolate strains, respectively. However, overall the compound 18d proved to be the most potent against all strains with 
TAвLE 1: In vitro antibacterial activities of monobactam derivatives $\mathbf{1 4}$ and $\mathbf{1 8}$ against selected Gram-negative bacteria.

\begin{tabular}{|c|c|c|c|c|c|c|c|c|c|c|}
\hline \multirow[b]{2}{*}{ Sample } & \multicolumn{10}{|c|}{$\mathrm{MIC}(\mu \mathrm{g} / \mathrm{mL})$} \\
\hline & $\begin{array}{l}\text { E. coli }{ }^{\mathrm{a}} \\
\text { (TEM-1) }\end{array}$ & $\begin{array}{c}\text { E. coli }{ }^{\mathrm{b}} \\
\text { (CTX-M15) }\end{array}$ & $\begin{array}{c}\text { K. } \mathrm{p}^{\mathrm{c}} \\
(\mathrm{SHV}-1)\end{array}$ & $\begin{array}{c}\text { K. } \mathrm{p}^{\mathrm{d}}(\mathrm{KPC}-3, \\
\text { TEM-1) }\end{array}$ & $\begin{array}{l}\text { E.c } e^{e} \\
(\mathrm{P} 99)\end{array}$ & $\begin{array}{c}\text { E.c }{ }^{f} \\
(\mathrm{AmpC})\end{array}$ & $\begin{array}{c}\text { A.b } \text { b }^{\mathrm{g}} \text { (OXA- } \\
23 / 40)\end{array}$ & $\begin{array}{c}\text { A.b } \\
\text { (OXA-24) }\end{array}$ & $\begin{array}{c}\text { P.a }{ }^{\mathrm{i}} \\
(\mathrm{KPC}-2)\end{array}$ & $\begin{array}{c}\text { P.a }{ }^{\mathrm{j}} \\
(\mathrm{AmpC})\end{array}$ \\
\hline Aztreonam & $>64$ & 16 & 64 & 64 & $>64$ & $>64$ & $>64$ & 32 & $>64$ & 16 \\
\hline Ceftazidime & $>64$ & $>64$ & $>64$ & $>64$ & $>64$ & $>64$ & $>64$ & $>64$ & $>64$ & $>64$ \\
\hline $14 a$ & 8 & 1 & 4 & 8 & 8 & 8 & 16 & 8 & 2 & 2 \\
\hline $14 b$ & 2 & 0.5 & 2 & 8 & 8 & 8 & 16 & 8 & 4 & 1 \\
\hline $14 \mathrm{c}$ & 0.5 & 0.5 & 32 & 64 & 32 & 64 & 16 & 32 & 4 & 2 \\
\hline 14d & 1 & 0.25 & 1 & 1 & 2 & 4 & 8 & 8 & 2 & 2 \\
\hline $14 \mathrm{e}$ & 0.25 & 0.25 & 1 & 4 & 2 & 4 & 8 & 4 & 1 & 0.5 \\
\hline $14 \mathrm{~g}$ & 1 & 0.5 & 32 & 64 & 64 & 32 & 32 & 16 & 16 & 1 \\
\hline $18 a$ & 0.5 & 0.125 & 16 & 64 & 8 & 64 & 8 & 32 & 1 & 1 \\
\hline $18 b$ & 0.25 & 0.25 & 8 & 64 & 16 & 64 & 8 & 16 & 2 & 1 \\
\hline $18 d$ & 8 & 1 & 4 & 8 & 8 & 8 & 16 & 8 & 2 & 2 \\
\hline $18 \mathrm{e}$ & 0.5 & 0.125 & 1 & 64 & 4 & 32 & 4 & 16 & 2 & 0.5 \\
\hline $18 f$ & 0.125 & 0.25 & 2 & 32 & 8 & 16 & 4 & 8 & 0.5 & 0.5 \\
\hline
\end{tabular}

${ }^{\mathrm{a}}$ E. coli clinical isolate; ${ }^{\mathrm{b}}$ E. coli $8739 ;{ }^{\mathrm{c}} \mathrm{K}$. pneumoniae clinical isolate; ${ }^{\mathrm{d}} \mathrm{K}$. pneumoniae $700603 ;{ }^{\mathrm{e}}$ E. cloacae clinical isolate; ${ }^{\mathrm{f}}$ E. cloacae $700323 ;{ }^{\mathrm{g}}$ A. baumannii clinical isolate; ${ }^{\mathrm{h}}$ A. baumannii $19606 ;{ }^{\mathrm{i}}$ P. aeruginosa clinical isolate; ${ }^{\mathrm{j}}$ P. aeruginosa 9027.

MIC values ranging from 1 to $16 \mu \mathrm{g} / \mathrm{mL}$, exhibiting the highest potency against E. Coli 8739 and lowest against A. baumannii clinical isolate.

\section{Conclusion}

We successfully synthesized eleven new monobactams with diverse structural variations at $\mathrm{N} 1, \mathrm{C} 3$, and $\mathrm{C} 4$ positions of the azetidinone ring. Thus, obtained final targets (14a-e, 14g, 18ab, and 18d-f) were evaluated for their antibacterial strength in vitro using ten different bacterial strains, and the results were compared with two reference antibiotics, aztreonam and ceftazidime. All compounds showed variable antibacterial activity against all tested bacteria; however, both strains of $E$. coli were most susceptible to the newly synthesized derivatives. Comparing the overall activity of the compounds, it can be visualized that the compounds $\mathbf{1 4 d}$ and $\mathbf{1 4} \mathbf{e}$ are more active in vitro than the reference antibiotics, aztreonam and ceftazidime, against all tested bacteria. Antimicrobial activities of the compounds demonstrated that changes made in the lactam ring structure are beneficial, for example, thiazole moiety proved to be better as compared to thiadiazole. In addition, these results clearly indicate that monobactams $14 \mathbf{d}$ and $14 \mathbf{e}$ are valuable lead compounds for the development of new potent antibiotics; most importantly, they may lead to antibacterial candidates against MDR Gram-negative bacteria.

\section{Data Availability}

The data used to support the findings of this study are included within the Supplementary Materials.

\section{Conflicts of Interest}

The authors declare that they have no conflicts of interest.

\section{Authors' Contributions}

Lili He and Lijuan Zhai are equal contributors to this work.

\section{Acknowledgments}

Ministry of Science and Technology, China, is gratefully acknowledged for the award of the foreign expert program to Dr. Haikang Yang and Dr. Zafar Iqbal.

\section{Supplementary Materials}

NMR spectra of key intermediates and final compounds. (Supplementary Materials)

\section{References}

[1] C. L. Tooke, P. Hinchliffe, E. C. Bragginton et al., " $\beta$-lactamases and $\beta$-lactamase inhibitors in the 21 st century," Journal of Molecular Biology, vol. 431, no. 18, pp. 3472-3500, 2019.

[2] J. M. Munita and C. A. Arias, "Mechanisms of antibiotic resistance," Microbiology Spectrum, vol. 4, no. 2, p. 37, 2016.

[3] E. Peterson and P. Kaur, "Antibiotic resistance mechanisms in bacteria: relationships between resistance determinants of antibiotic producers, environmental bacteria, and clinical pathogens," Frontiers in Microbiology, vol. 9, no. 2928, p. 21, 2018.

[4] R. Köck and C. Cuny, "Multiresistente erreger bei tier und mensch," Medizinische Klinik-Intensivmedizin und Notfallmedizin, vol. 115, no. 3, pp. 189-197, 2020.

[5] K. Bush and P. A. Bradford, " $\beta$-lactams and $\beta$-lactamase inhibitors: an overview," Cold Spring Harbor Perspectives in Medicine, vol. 6, no. 8, Article ID a025247, 2016.

[6] K. Bush and J. F. Fisher, "Epidemiological expansion, structural studies, and clinical challenges of new $\beta$-lactamases from gram-negative bacteria," Annual Review of Microbiology, vol. 65, p. 24, 2011.

[7] T. H. O. Leite, M. F. Saraiva, A. C. Pinheiro, and M. V. N. de Souza, "Monocyclic $\beta$-lactam: a review on synthesis and potential biological activities of a multitarget core," Mini-Reviews in Medicinal Chemistry, vol. 20, no. 16, pp. 1653-1682, 2020.

[8] L. Decuyper, M. Jukič, I. Sosič, A. Žula, M. D’Hooghe, and S. Gobec, "Antibacterial and $\beta$-lactamase inhibitory activity of monocyclic $\beta$-lactams," Medicinal Research Reviews, vol. 38, no. 2, pp. 426-503, 2018. 
[9] R. Vardanyan and V. Hruby, Synthesis of Best-Seller Drugs, Academic Press-Elsevier, Cambridge, MA, USA, 1st edition, 2016.

[10] R. K. Shields and Y. Doi, “Aztreonam combination therapy: an answer to metallo- $\beta$-lactamase-producing gram-negative bacteria?" Clinical Infectious Diseases, vol. 71, no. 4, pp. 1099-1101, 2020.

[11] M. Yasmin, D. E. Fouts, M. R. Jacobs et al., "Monitoring ceftazidime-avibactam and aztreonam concentrations in the treatment of a bloodstream infection caused by a multidrugresistant Enterobacter sp. carrying both Klebsiella pneumoniae carbapenemase- 4 and New Delhi metallo- $\beta$-lactamase1," Clinical Infectious Diseases, vol. 71, no. 4, pp. 1095-1098, 2020.

[12] S. M. Drawz, K. M. Papp-Wallace, and R. A. Bonomo, "New $\beta$-lactamase inhibitors: a therapeutic renaissance in an MDR world," Antimicrobial Agents and Chemotherapy, vol. 58, no. 4, pp. 1835-1846, 2014.

[13] F. Reck, A. Bermingham, J. Blais et al., "Optimization of novel monobactams with activity against carbapenem-resistant Enterobacteriaceae-identification of LYS228," Bioorganic \& Medicinal Chemistry Letters, vol. 28, no. 4, pp. 748-755, 2018.

[14] M. E. Falagas, A. D. Mavroudis, and K. Z. Vardakas, "The antibiotic pipeline for multi-drug resistant gram negative bacteria: what can we expect?" Expert Review of Anti-infective Therapy, vol. 14, no. 8, pp. 747-763, 2016.

[15] Z. M. Thu, J. Sun, J. Ji et al., "Synthesis and antibacterial evaluation of new monobactams," Bioorganic \& Medicinal Chemistry Letters, vol. 39, Article ID 127878, 2021.

[16] K. Burkhard, W. Irith, S. Guido et al., "Amidine substituted beta - lactam compounds, their preparation and use as antibacterial agents," Pat. Appl. EP2013/051217 Pat. WO/2013/ $110643 \mathrm{~A} 1,2013$.

[17] K. Sakagami, K. Iwamatsu, K. Atsumi, and M. Hatanaka, "Synthetic cephalosporins. VII. Synthesis and antibacterial activity of 7-((Z)-2-(2-aminothiazol-4-yl)-2-(3-(3-hydroxy-4pyridon-1-yl)-3-carboxypropoxyimino)acetamido)-3-(1,2,3thiadiazol-5-yl)-thiomethyl-3-cephem-4-carboxylic acid and its related compounds," Chemical and Pharmaceutical Bulletin, vol. 38, no. 12, pp. 3476-3479, 1990.

[18] M. A. Wikler, Methods for Dilution Antimicrobial Susceptibility Tests for Bacteria that Grow Aerobically; Approved Standard, Vol. 29, Clinical and Laboratory Standards Institute, Wayne, PA, USA, 2009.

[19] J. M. Ready and E. N. Jacobsen, "Asymmetric catalytic synthesis of $\alpha$-aryloxy alcohols: kinetic resolution of terminal epoxides via highly enantioselective ring-opening with phenols," Journal of the American Chemical Society, vol. 121, no. 25, pp. 6086-6087, 1999.

[20] K. B. Hansen, P. Rabbat, S. A. Springfield, P. N. Devine, E. J. J. Grabowski, and P. J. Reider, "Asymmetric synthesis of cis-aminochromanol," Tetrahedron Letters, vol. 42, no. 50, pp. 8743-8745, 2001.

[21] T. Hashiyama, A. Watanabe, H. Inoue et al., "Reactions of 3phenylglycidic esters. V: Reaction of methyl 3-(4-methoxyphenyl)glycidate with 2-nitroaniline and synthesis of 1,5benzodiazepine derivatives," Chemical and Pharmaceutical Bulletin, vol. 33, p. 8, 1985.

[22] K. Yamawaki, T. Nomura, T. Yasukata et al., "A novel series of parenteral cephalosporins exhibiting potent activities against Pseudomonas aeruginosa and other Gram-negative pathogens: synthesis and structure-activity relationships," Bioorganic \& Medicinal Chemistry, vol. 15, no. 21, pp. 6716-6732, 2007.
[23] H. Tang, W. Liu, F. Tang et al., "Patent Application WO2017/ 106064," 2017. 